Check for updates

Cite this: Mater. Adv., 2022, 3,1415

Received 23rd July 2021, Accepted 10th December 2021

DOI: 10.1039/d1ma00639h

rsc.li/materials-advances

\title{
Selenium nanoparticles: a review on synthesis and biomedical applications
}

\author{
Neha Bisht, Priyanka Phalswal (D) and Pawan K. Khanna (D) *
}

\begin{abstract}
Selenium is a trace and essential micronutrient for the health of humans, animals, and microorganisms. Recently, selenium nanoparticles (SeNPs) attracted the interest of many researchers due to their biocompatibility, bioavailability, and low toxicity. Therefore, due to their higher bioactivity selenium nanoparticles are largely being used in various biomedical applications. Generally, selenium nanoparticles can be synthesized by physical, chemical, and biological methods. However, the biologically synthesized SeNPs demonstrate greater compatibility with human organs and tissues. The effect of size, shape, and the method employed for their synthesis on their applications in biological systems has been explored by many researchers. This review discusses various synthesis methods employed for their preparation and highlights their applications in the biomedical field such as in the treatment of fungal, bacterial, and parasitic infections, cancer, and diabetes. They can also act as chemopreventive agents, anti-inflammatory agents, and antioxidants.
\end{abstract}

\section{Introduction}

Elemental selenium (Se) has great importance in the fields of physics, chemistry, and biology. Naturally, selenium exists in two forms: inorganic (selenite and selenate) and organic (selenomethionine and selenocysteine). Selenium is found in the form of both crystalline and amorphous polymorphic structures in nature. Monoclinic and trigonal selenium are the crystalline forms. Monoclinic selenium (m-Se) is red in color and contains rings of $\mathrm{Se}_{8}$. Based on different packings, it exists in three allotropic forms $(\alpha, \beta$ and $\gamma)$. Trigonal selenium (t-Se) is black in colour and the most stable crystalline form at room temperature. Red amorphous (a-Se), black amorphous and vitreous selenium are the non-crystalline forms of selenium. ${ }^{1}$ The crystal structures of $\mathrm{t}$-Se and $\mathrm{m}$-Se are presented in Fig. 1(a and b), respectively. ${ }^{2}$ Selenium, a part of selenoproteins and selenocompounds within the human body, plays a critical role in reproduction, DNA synthesis, thyroid hormone, metabolism, and protection from infections and oxidative damage. It has many industrial and commercial applications. Due to its high photoconductivity and low melting point, it possesses great catalytic activity towards organic hydration and oxidation reactions. Selenium is an essential trace element in the human body but the margin between its usefulness and toxicity is very slender. The United Kingdom group of vitamins and minerals

Nano Chemistry and Quantum Dots $R \& D$ Laboratory, Department of Applied Chemistry, Defence Institute of Advanced Technology (DIAT), Ministry of Defence, Govt. of India, Girinagar, Pune-411025, India.

E-mail: pawankhanna2002@yahoo.co.in recommended the daily intake of selenium by women and men should be $60 \mu \mathrm{g}$ and $70 \mu \mathrm{g}$, respectively. ${ }^{3}$ A daily intake of more than $400 \mu \mathrm{g}$ could be toxic which leads to a disorder known as selenosis. ${ }^{3-5}$ Selenium plays a key role as a biochemical component of glutathione peroxidase, an enzyme responsible for the protection of essential SH-groups and for the decomposition of peroxides, thereby acting as an antioxidant. The bactericidal activity of selenium is because of its capacity to catalyse the oxidation of intracellular thiols, causing death of microscopic organisms. ${ }^{6-8}$ Selenium, as one of the fundamental minor components, is affirmed to improve the action or restore the activity of the seleno-catalyst and glutathione peroxidase in prevention of free radical harm to cells and tissues in vivo. ${ }^{9-12}$ It is widely utilized in nutritional supplements as well as a potential nutrient in fertilizers. ${ }^{13}$ A selenium free diet leads to malfunctioning of the liver and hemolytic processes. Se deficiency leads to many diseases such as Kashin-Beck disease, ${ }^{14}$

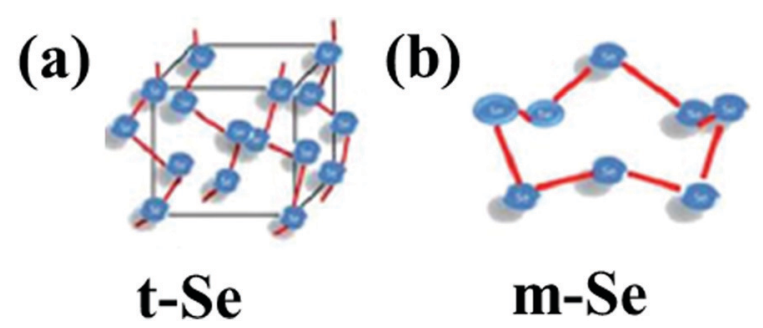

Fig. 1 General representation of the crystal structure of (a) t-Se and (b) $\mathrm{m}$-Se. Reproduced from ref. 2 with permission from The Royal Society of Chemistry, copyright 2015 
neurological disorders, ${ }^{15}$ and chronic degenerative diseases. ${ }^{16}$ Selenium supplements can prevent diseases, such as viral infections, ${ }^{17}$ immune system dysfunction, ${ }^{18}$ and neural function loss. ${ }^{19}$ The recent boom in nanotechnology furnished an indefinite number of applications of metal nanoparticles in biomedicine. Metal NPs of Au and Ag, have immense medicinal benefits but are costlier to synthesize, whereas the synthesis of Se nanoparticles (SeNPs) is economical and they can be integrated with other biological agents to enhance their biological properties. Vahdati et $a .^{20}$ demonstrated the synergistic antimicrobial effect of SeNPs and lysozymes. Due to their higher surface-tovolume ratio at the nano-level, the surface of the particles is more exposed which leads to an enhanced activity of selenium more profoundly in the nano-regime. SeNPs show promising potential as antioxidants, cancer therapeutic agents, and drug carriers in biological applications. ${ }^{21}$ Several studies have supported their anticancer, ${ }^{22}$ antioxidant, ${ }^{21}$ antimicrobial, ${ }^{23-25}$ and anti-biofilm properties. ${ }^{26}$ Use of nano-Se medication in the therapy of Huntington's disease has given promising results. ${ }^{27}$ SeNPs possess unique semiconducting, photoelectric and X-ray-sensing properties, and are used in photocells, photocopying, photometers, and xerography. ${ }^{28}$ Their importance in renewable energy devices has also been greatly mentioned. ${ }^{29}$ Additionally, selenium nanoparticles (SeNPs) are environmentally important because of their mercury capturing properties. $^{30}$

The absorption profile of selenium indicates that nanoselenium can lead to a blue shift in the absorption spectrum and the range of this shift can vary from preparation to preparation. Thus, it is deduced that the bandgap of Se increases from $1.7 \mathrm{eV}$ in bulk to $3.3 \mathrm{eV}$ in the nano-range. ${ }^{31}$ The least toxic form of selenium is elemental Se, and hence its nano-form has attracted significant attention. Interestingly, functionalized SeNPs exhibit less cytotoxicity than their other forms such as selenate, selenite, selenoproteins, and inorganic selenium. $^{32,33}$ In clinical trials, instead of conventional selenium sources, elemental nano-sized selenium can be a better alternative. Fig. 2 demonstrates the decrease of cytotoxicity as the selenium nanoparticle size increases. ${ }^{34}$ SeNPs are highly biologically active, ${ }^{35}$ anti-hydroxyl radicals, ${ }^{36}$ and chemopreventive, ${ }^{32,37}$ have a detoxifying effect on heavy metal exposure, ${ }^{38}$ and prevent DNA oxidation. ${ }^{39}$

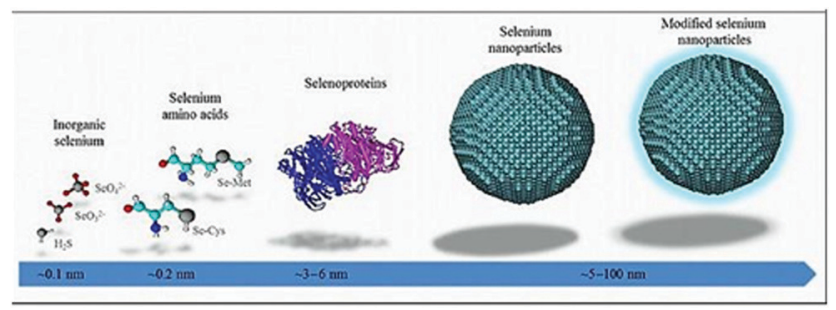

Increasing Cvtotoxicity

Fig. 2 Extent of cytotoxicity from various sources of selenium with respect to their size. Reproduced from ref. 34 with permission from Science Elsevier, copyright 2017.
It has been suggested by various researchers that impetus to conduct research on SeNPs is greatly desired owing to their tremendous applications in the biomedical field due to their excellent antibacterial activity, sometimes even more effective than Ag NPs. ${ }^{40-42}$ SeNPs have been synthesized in various forms such as nanowires, nanorods, and nanotubes through various methods such as sonochemical, ${ }^{43}$ refluxing, microwave, ${ }^{44}$ hydrothermal, ${ }^{45}$ gamma irradiation, ${ }^{46}$ pulsed laser ablation, ${ }^{13,47,48}$ and physical evaporation approaches. ${ }^{49-51}$ The precursors mostly used in these methods are sodium selenite, sodium selenate, sodium selenosulphate, selenous acid and selenium oxide. Use of these precursors is often preferred because selenium in selenite and selenate forms has a hazardous effect even at extremely low concentrations and gets accumulated in the bio-system. In recent times Khanna et al. have demonstrated exclusive use of 1,2,3-selenadiazole as a source of selenium for a variety of semiconductor NP ink/ quantum dots including selenium nanoparticles. ${ }^{2,52-55}$ Converting them to biologically and technologically important SeNPs can help in revitalizing the environment and protect from contamination of Se compounds. Various reviews on the biological applications of selenium nanoparticles and their compound $s^{56}$ have been published in recent years while focusing on their biological synthesis methods. ${ }^{57}$ This review emphasizes the different synthesis methods of SeNPs and their advantages and disadvantages over each other. The authors also present a detailed discussion of various biological applications of SeNPs such as anti-cancerous, antioxidative, antidiabetic, antiparasitic, antimicrobial, antibacterial, antifungal and chemopreventive agents.

\section{Synthesis methods}

The synthesis of SeNPs by various methods has been reported. These methods can be broadly divided into two categories, namely biological and chemical reduction. Biological reduction methods include reduction of various organic/inorganic compounds of selenium via biological agents such as bacteria or plant extracts and their conversion to non-toxic and beneficial SeNPs. Chemical reduction uses chemical reducing agents. This method can further be classified depending upon the energy source used or the apparatus employed for the reaction. Researchers have reported mainly hydrothermal, microwave, and sonochemical methods in this category. This broad classification is presented in Fig. 3 and then these methods are further discussed in sub-sections.

\subsection{Chemical reduction method}

Among the vast varieties of synthesis methods reported, reduction of Se salts is the most common and simplest method to synthesize SeNPs. ${ }^{58}$ The sources can be natural compounds from plants or microorganisms $s^{59,60}$ or reagents/chemicals having the ability to cause reduction in the oxidation state such as ascorbic acid. ${ }^{61}$ However, the nanoparticles (NPs) synthesized from natural compounds are found to be less toxic than those 

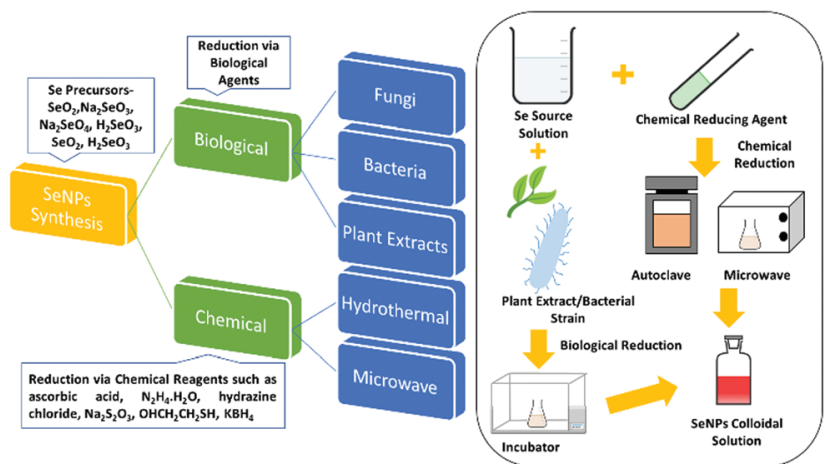

Fig. 3 A systematic representation of various synthesis methods of selenium nanoparticles.

prepared by employing chemicals. ${ }^{62}$ In this section, synthesis via the chemical method is discussed and synthesis from natural compounds, i.e., biogenic reduction, will be discussed in a later section. Chemical reduction uses chemical compounds that reduce the element, its salt or compounds and the size is controlled by use of surfactants or growth terminating reagents such as polyvinylchloride (PVP), folic acid, etc. ${ }^{63}$ to obtain a stable colloidal solution of SeNPs desired for various applications. Taking $\mathrm{SeO}_{2}$ as the precursor, El-ghazaly et al. ${ }^{64}$ synthesized spherical SeNPs about $13 \mathrm{~nm}$ in size where PVP served as the stabilising agent and $\mathrm{KBH}_{4}$ as the reducing agent in ice-cold solution. The appearance of orange colour indicated the formation of $\alpha$-Se. The particle shape and size was $<10 \mathrm{~nm}$ in diameter based on transmission electron microscopy (TEM) analysis. Gao et al. ${ }^{36}$ reported the use of protein molecules to stabilise hollow SeNPs formed via reduction of sodium selenite with mercaptoethanol. The reaction was carried out at a low temperature $\left(<10{ }^{\circ} \mathrm{C}\right)$ and continued for almost 3 days. Particles with an average diameter of nearly $30 \mathrm{~nm}$ and a shell thickness of $4 \mathrm{~nm}$ were identified and the characteristic binding energy of $55.3 \mathrm{eV}$ corresponding to $\mathrm{Se}(3 \mathrm{~d})$ from the X-ray photoelectron spectroscopy (XPS) spectrum confirmed Se in the zero-valent state.

In another study, Tran et al. ${ }^{65}$ reduced sodium selenite by ascorbic acid using polyvinyl alcohol (PVA) as the stabilising agent, resulting in an average particle size of $70 \mathrm{~nm}$ as observed from dynamic light scattering (DLS) measurements. The absorption was observed in the wavelength range 250 to $450 \mathrm{~nm}$, and the non-appearance of a sharp peak was attributed to the non-metallic nature of Se. The formation of elemental selenium was also confirmed by a characteristic XPS peak at $54.2 \mathrm{eV}$ for Se (3d). Khalid et al. ${ }^{66}$ repeated the same experiment for PVA capped SeNPs to study their application in cellular imaging. They observed an XPS peak at almost the same value as reported by Tran et al. ${ }^{65} \mathrm{~A}$ similar UV-Vis absorption band was observed, and the PL showed an emission at $580 \mathrm{~nm}$. By using the same chemical sources and reagents along with chitosan as an additional stabilising agent, Boroumand et al. $^{67}$ obtained spherical NPs of sizes 136 and $195 \mathrm{~nm}$, respectively, where the UV-Vis spectra showed absorption peaks at 264 and $310 \mathrm{~nm}$. Similarly, by changing the stabilising agent to polysorbate 20 , Vahdati et al. ${ }^{20}$ obtained a characteristic UV absorption peak at $265 \mathrm{~nm}$ consistent with a previous report but with a much smaller particle size in the range of 35-45 nm in comparison to that obtained by using PVA or chitosan. Likewise, Shah et $a l .{ }^{68}$ also used PVA as the stabilizer to obtain SeNPs of $50-100 \mathrm{~nm}$ size. The authors for the first time reported that sodium selenosulphate responded to the acrylonitrile monomer, forming SeNPs. By replacing acrylonitrile with acetonitrile, the authors could not isolate Se nanoparticles. This suggests that the nitrile group was not directly involved in the reaction. Using hyperbranched polysaccharide as the stabiliser in the reaction of selenious acid with ascorbic acid in water led to formation of highly stable ( $>1$ month) SeNPs with an average size of about $24 \mathrm{~nm}$ which was calculated through DSC. ${ }^{69}$ Lin et $a l .{ }^{70}$ used a very mild reducing agent, i.e., dilute $\mathrm{SO}_{2}$ solution, and selenious acid as the selenium source. Selenous acid being a strong oxidising agent gets easily reduced by $\mathrm{SO}_{2}$. Sodium dodecyl sulfate (SDS) was used as the stabilizer and the reaction temperature was kept at $80^{\circ} \mathrm{C}$. The variation in particle size with time was studied by TEM. The particle size varied from $30 \mathrm{~nm}$ to $200 \mathrm{~nm}$ in a time span of $30 \mathrm{~s}$ to 4 minutes. The article by $\mathrm{Yu}$ et $a l^{71}{ }^{71}$ highlighted the use of sodium thiosulfate as the reducing agent. Reaction of selenium dioxide with sodium thiosulfate in the presence of SDS for about $4 \mathrm{~h}$ in ambient conditions yielded monodisperse SeNPs of about $70 \mathrm{~nm}$ size as estimated from the TEM images. Huang et $a l^{72}$ studied the effect of the size of SeNPs on their inhibiting action towards methicillin-sensitive and methicillin-resistant Staphylococcus aureus (MSSA and MRSA). For this, they synthesized spherical SeNPs of size ranging from 43 to $205 \mathrm{~nm}$ by varying the ratio of $\mathrm{SeO}_{2}$, the reducing agent sodium thiosulphate and the capping agent PVA. From the antibacterial and cytotoxicity studies, they observed the highest efficacy for $81 \mathrm{~nm}$ sized particles. The synthesized particles were found to be spherical and mono-disperse from the scanning electron microscopy (SEM) images. ${ }^{72}$ The SeNPs synthesized using the chemical reduction method by the use of polysaccharides as stabilizing/reducing agents was critically reviewed by Shi et al. ${ }^{73}$

2.1.1. Microwave synthesis. The microwave method has now become one of the general chemical methods used for materials synthesis. The method is rapid, effortless, inexpensive, clean, provides the end product in high yield and is often termed as a green synthesis route. Over conventional methods where heating takes place via conduction, microwave heating is more efficient as heating through microwave radiation is more uniform as the radiation interaction is directly with the molecules. These advantages led researchers to exploit this method for the synthesis of SeNPs as well. However, the literature available on the utilization of microwave energy for preparation of SeNPs is very scarce. One of us previously reported the synthesis of both red and black SeNPs from cycloocteno-1,2,3selenadiazole by decomposition via microwave energy. 1,2,3Selenadiazole was taken in diphenyl ether with oleic acid as the surfactant. In 10-12 minutes the formation of amorphous red Se particles was confirmed by an UV-absorption band at $400 \mathrm{~nm}$, and when the reaction proceeded further for a few 
more minutes, the band shifted to $490 \mathrm{~nm}$ and black Se was formed. The corresponding PL peaks were observed at 430 and $510 \mathrm{~nm}$ with broad emission profiles. The red Se showed a trigonal structure as deduced from the XRD measurements where the peaks are observed at $2 \theta$ values of $23.92^{\circ}, 30.11^{\circ}$, $41.64^{\circ}, 44.16^{\circ}, 45.89^{\circ}, 52.31^{\circ}, 56.31^{\circ}, 56.55^{\circ}$ and $62.07^{\circ}$. For the black monoclinic Se, the peaks were observed at $2 \theta$ values of $21.80^{\circ}, 24.80^{\circ}, 33.19^{\circ}, 43.51^{\circ}, 46.79^{\circ}$ and $62.70^{\circ}$. Hence, by simply varying the reaction time, various polymorphic forms of Se can be achieved. ${ }^{2}$ In another report, $\mathrm{SeCl}_{4}$ was taken as the source, reduced using hydrazine, where the polymer SDS was used as the surfactant, and exposed to microwave irradiation for 4-5 minutes at $750 \mathrm{~W}$ to obtain black SeNPs. Several researchers have used microwave irradiation to synthesize SeNPs with narrow size distribution. ${ }^{74}$ Mellinas et al. ${ }^{75}$ for the first time reported the use of Theobroma cacao L. bean shells (CBS) as the reducing and stabilising agent for synthesis of SeNPs. The authors have designed a model using a central composite design technique to optimize the reaction conditions. The data for 23 different samples were fed which included parameters such as time, power, amount of precursor, i.e., $\mathrm{Na}_{2} \mathrm{SeO}_{3}$, Z-potential and crystallite size. Based on this model, the optimal reaction conditions were obtained as 15.6 min, 788.6 W, $0.14 \mathrm{~g}$ of $\mathrm{Na}_{2} \mathrm{SeO}_{3}$ and $50 \mathrm{~mL}$ CBS extract solution which yielded particles of $\sim 42 \mathrm{~nm}$ diameter. The TEM images revealed uniformly distributed spherical particles of 1-3 nm diameter which were found to be stable for 2 months. This attempt opens up a new way in the synthesis of SeNPs via microwave and also highlights the technological applications of SeNPs in food and medicine. Panahi-Kalamuei et al. ${ }^{31}$ reported the synthesis of SeNPs using chemical compounds such as sodium dodecyl sulfate (SDS), polyethylene glycol (PEG 600 ) and cetyltrimethylammonium bromide (CTAB). $\mathrm{SeCl}_{4}$ was used as the starting material which on dissolving in water produces selenious acid which was reduced using hydrazine hydrate. The reduction potential of $\mathrm{Se}^{4+} / \mathrm{Se}$ is $0.74 \mathrm{eV}$ and that of $\mathrm{N}_{2} \mathrm{H}_{4} \cdot \mathrm{H}_{2} \mathrm{O} / \mathrm{N}_{2}$ is $-1.16 \mathrm{eV}$. Hence, the electrode potential is $1.9 \mathrm{eV}$. Therefore, they chose hydrazine hydrate as the reducing agent and microwaved the mixture for $4 \mathrm{~min}$ at $750 \mathrm{~W}$ to obtain 5-25 nm particles using SDS. They mentioned that when surfactants like CTAB and PEG are used bigger sized and agglomerated particles will be formed. According to them, this was because $\mathrm{Se}^{4+}$ ions present in the reaction media are more stabilised by the anionic surfactant. A similar trend was observed on increasing/decreasing the reaction time/wattage.

2.1.2. Hydrothermal method. The hydrothermal method is not widely popular for the synthesis of biologically compatible SeNPs as reflected from the scarcity of literature. However, the available reports showed that very small sized particles, i.e., 10-20 nm, can be achieved by this method. Shin et al. ${ }^{76}$ reported the use of cellulose nanocrystals for the first time in reduction of $\mathrm{Na}_{2} \mathrm{SeO}_{3}$ to obtain SeNPs having size in the range of $10-20 \mathrm{~nm}$. The method is very convenient and eco-friendly. Another example of environment-friendly synthesis is the synthesis reported by Abbasian et al. ${ }^{77}$ where they used coffee bean extract to reduce $\mathrm{Na}_{2} \mathrm{SeO}_{3}$ to Se. The reaction completed in
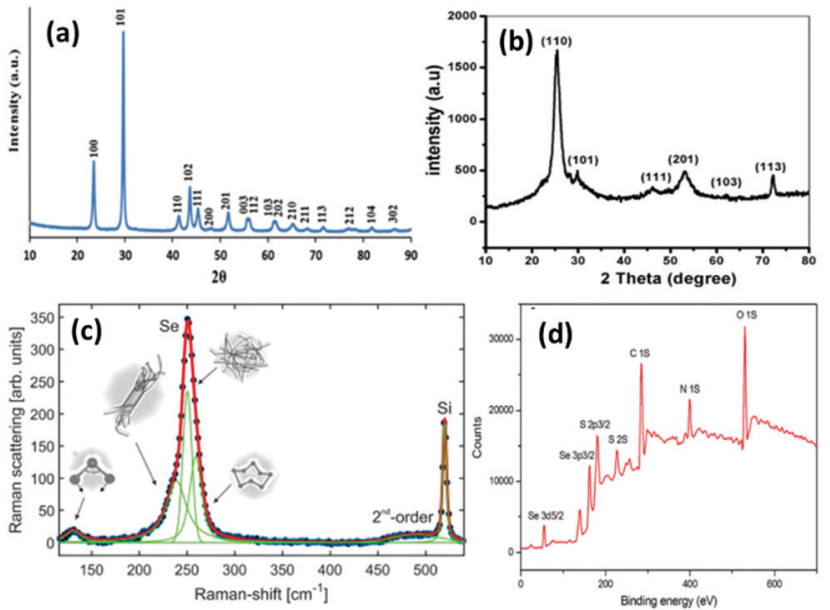

Fig. 4 (a) XRD pattern of SeNPs synthesized via the hydrothermal method. Reproduced from ref. 78 with permission from Science Elsevier, copyright 2013, (b) XRD pattern of SeNPs synthesized using drumstick extract. Reproduced from ref. 105 with permission from John Wiley and Sons, copyright 2019, (c) Raman spectra of Se representing the presence of various phases at different energies. Reproduced from ref. 48 with permission from Springer Nature, Copyright 2019. (d) XPS spectrum of L-cysteine capped SeNPs. Reproduced from ref. 109 with permission from RSC Publications, copyright 2017.

15 minutes and at a medium temperature. Spherical nanoparticles of $\sim 15 \mathrm{~nm}$ average size were synthesized by reduction of $\mathrm{Na}_{2} \mathrm{SeO}_{3}$ via hydrazine chloride. The XRD peaks (Fig. 4b) at $2 \theta$ values of $23^{\circ}, 28^{\circ}, 42^{\circ}, 46^{\circ \circ}$ and $52^{\circ}$ confirmed the formation of black Se in the tri-dimensional phase. ${ }^{78}$ Glucose and $\mathrm{Na}_{2} \mathrm{SeO}_{3}$ were sealed in an autoclave and reacted in an ethylene glycol and water mixture at $85{ }^{\circ} \mathrm{C}$ for 45 minutes. From this reaction, Chen et al. ${ }^{79}$ obtained t-Se spherical nanoparticles of a $320 \mathrm{~nm}$ average size which were further converted into nanorods on prolonged reaction.

\subsection{Biogenic reduction}

Green synthesis of metal NPs have gained the attention of researchers in the last two decades. Despite the various advantages of SeNPs over organic and inorganic selenium compounds, the main problem is their poor cellular intake. Therefore, it is desirable to synthesize SeNPs via a biological route to offer improved biocompatibility and stability. The previous methods mentioned above require chemical reducing and stabilising agents which may be toxic and can hinder their utilization in biological systems. Generally, it is believed that biological agents from plant extracts and microorganisms represent a superior option in contrast to chemical methods to satisfy the increasing demand for low-cost and nonhazardous preparation methods. It has been reported that biological extracts act as bio-reducing agents, as well as stabilizers for nanoparticles. There is a tremendous amount of literature available on the biosynthesis of SeNPs. ${ }^{80-87}$ Biological agent mediated synthesis is easy as this does not require special apparatus and conditions. These biological reagents include bacteria, fungi, algae, protein molecules and plant extracts. For 
instance, several researchers have reported the synthesis of SeNPs using fenugreek extract, ${ }^{88}$ Cassia auriculata extract, ${ }^{89}$ E. officinalis fruit extract, ${ }^{90}$ microbial polymers, ${ }^{91}$ Bacillus sp. B2, ${ }^{92}$ Saccharomyces cerevisiae var. boulardii yeast cells, ${ }^{93}$ Penicillium chrysogenum, ${ }^{94}$ Penicillium expansum, ${ }^{95}$ Vitis vinifera aq., ${ }^{96}$ Withania somnifera extract, ${ }^{97}$ Azadirachta indica, ${ }^{98}$ Aloe vera leaf extract, ${ }^{99}$ Burkholderia fungorum, ${ }^{100}$ Diospyros montana leaf extract, ${ }^{101}$ lemon leaf extract, ${ }^{102}$ or bacteria grown from Mueller-Hinton broth ${ }^{103}$ as reducing agents with incubation of the precursor mixture for a day or two. However, the use of plant extracts is even more cost effective than using bacteria or fungi as bacterial culture and isolation requires techniques, experience, and special equipment. With this method, highquality SeNPs can be produced without requiring specific equipment, with less or no product wastage, and without the need of a large amount of solvent. Hence, such methods are considered as single-step, inexpensive and eco-friendly. Plant extracts contain terpenes, flavonoids, tannins, coumarins, cinnamic acid, phenolic acid, vitamins, sterols, polysaccharides, enzymes, proteins, etc. which can act both as reducing and as stabilizing agents. Recently, a few review articles brought out the importance of plant-based SeNPs, the simplicity in the synthesis and the feasibility for biological applications. ${ }^{57,104}$ Moreover, preparation of SeNPs using medicinal plants may enhance their beneficial properties. These biological catalysts are vital environmentally as they reduce the toxic oxyanions present in the environment into non-toxic elemental selenium. Fig. 4b shows the XRD pattern of SeNPs synthesized using drumstick extract showing peaks at $2 \theta$ values of $25.38^{\circ}, 29.98^{\circ}$, $46.1^{\circ}, 53.00^{\circ}, 62.38^{\circ}$, and $72.00^{\circ}$ due to [100], [101], [111], [201], [103], and [113] planes, respectively, showing the crystalline nature of Se. ${ }^{105}$ However, the XRD diffraction peaks for red Se prepared from Muller-Hinton broth were obtained at $23.78^{\circ}$, $29.79^{\circ}$, and $43.88^{\circ}$ indexed to the face centred cubic (fcc) planes [100], [101], and [102], respectively, and UV absorption was observed at $263 \mathrm{~nm} .{ }^{103}$ The most intense peak for the hexagonal phase of SeNPs appears at $29.73^{\circ} .^{106}$ The characteristic Raman peak for elemental Se is observed at $254 \mathrm{~cm}^{-1}$. However, a slight shift may be observed depending upon the polymorphic forms of Se. Fig. 4c shows the Raman spectra of SeNPs synthesized via the laser ablation method which shows a mixture of various phases. ${ }^{48}$ The authors interpreted that the peak at the lowest frequency of $131 \mathrm{~cm}^{-1}$ corresponds to bending vibrations. The Se-Se stretching in crystalline Se chains appears at $237 \mathrm{~cm}^{-1}$ and $250 \mathrm{~cm}^{-1}$. The peak at $259 \mathrm{~cm}^{-1}$ was reported to be due to the vibration modes of in the $\mathrm{Se}_{8}$ crown structure. In general, depending upon the intensity of a particular peak, one can estimate the type of Se formed. Piacenza et al. ${ }^{107}$ suggested the use of biologically synthesized SeNPs in bio-imaging. They synthesized SeNPs from yeast extract which exhibited a strong photoluminescence emission in the blue-red region of the visible spectrum and a luminescence lifetime comparable to those of mostly used fluorophores. Afzal et al. ${ }^{108}$ reported the use of various cyanobacterial strains for the biogenic synthesis of SeNPs and studied their antioxidant properties. Out of the many strains used, Arthrospira indica SOSA-4 was suggested to be the best strain as it yielded SeNPs of $11.8 \mathrm{~nm}$ size and improved the antioxidant activity. When heated for a few minutes, reaction of L-cystine with selenious acid yielded cystine capped SeNPs whose size was determined by the DLS technique and valency was confirmed by the XPS spectra. The appearance of peaks at $55.5 \mathrm{eV}$ and $161.5 \mathrm{eV}$ for $\mathrm{Se} 3 \mathrm{~d}_{5 / 2}$ and $\mathrm{Se} 3 \mathrm{P}_{3 / 2}$, respectively, affirms Se in the zero-valent state. The XPS spectrum is shown in Fig. 4 d. ${ }^{109}$

In another report, Ramamurthy et $a .^{88}$ prepared 100-150 nm SeNPs by both chemical and biogenic methods. They observed that the size obtained from the biogenic method was slightly bigger than that achieved by the chemical method, yet the biogenic method proved to be more efficient mainly because biological strains are a combination of various reducing and stabilising agents. For the synthesis of SeNPs, researchers have mostly reported the use of biogenic/biotic reduction. The various biological agents used along with the precursor and reaction conditions are summarized in Table 1.

\section{Biomedical applications}

The biomedical applications of SeNPs have attracted global interest of many researchers due to their importance at cellular and tissue levels. It is well known that excessive production of toxic reactive oxygen species (ROS) can be triggered by various abiotic stresses, thus causing several diseases, due to damaged essential nutrients such as carbohydrates, proteins, and lipids. ${ }^{110}$ The continuous rise in diseases like cancer, diabetes, and bacterial infections is threatening the worldwide healthcare system. Currently, treatment of cancer needs various kinds of therapies such as chemotherapy, radiotherapy, or a combination of both to reduce the global death rate. ${ }^{111,112}$ The adverse effects of such therapies generally are of great concern. ${ }^{113}$ It has been documented that Se supplements alongside regular anticancer treatments upgraded the productivity of chemotherapeutic medications, declining results and enhancing the generic state of the patients. ${ }^{114-116}$ The new clinical preliminaries have assessed the well-being and efficiency of selenium, both in viability and toxicity of normal anticancer treatments. ${ }^{117}$ Numerous in vivo and in vitro studies at the supranutritional level have exhibited an anticancerous impact by selenium. ${ }^{118,119}$ Davis et al. ${ }^{120}$ reported that the frequency of liver malignancy can be decreased by $35 \%$ on consuming supplements of selenite salt. A few studies revealed that, by taking $200 \mu \mathrm{g}$ of selenium each day, as Se yeasts, the risk of colorectal, lung, and prostate cancers has decreased. ${ }^{121}$ Similarly, Se supplements also reduce the stomach malignancy risk. ${ }^{122}$ It has been reported that a lower dosage of selenoprotein (SelP) can increase the risk of cancer in prostate, throat, kidney, colon, and lungs. ${ }^{123}$ Selenium rich Brassica and Allium plants lessen the risk of colon malignant growth. ${ }^{121}$ Despite having such advantages these organic and inorganic sources of selenium exert higher toxicity and possess lower biocompatibility. To overcome these issues, SeNPs came to the limelight. 
Table 1 Summary of the reactions carried out by various researchers for synthesizing SeNPs using different biological sources

\begin{tabular}{|c|c|c|}
\hline $\begin{array}{l}\text { S. } \\
\text { no. }\end{array}$ & $\begin{array}{l}\text { Se } \\
\text { precursor }\end{array}$ & Biological agent/extract origin \\
\hline 1 & $\mathrm{SeO}_{2}$ & Bacillus licheniformis \\
\hline 2 & $\mathrm{SeO}_{2}$ & Bacillus licheniformis \\
\hline 3 & $\mathrm{Na}_{2} \mathrm{SeO}_{3}$ & Azadirachta indica \\
\hline 4 & $\mathrm{SeO}_{2}$ & $\begin{array}{l}\text { Trigonella foenum-graecum leaf } \\
\text { extract }\end{array}$ \\
\hline
\end{tabular}

Reaction

conditions

Morphology and size of particles Applications

Ref.

Incubated at Spherical with a diameter of 10- Antimicrobial against foodborne

103

$37^{\circ} \mathrm{C}$ for $48 \mathrm{~h} 50 \mathrm{~nm}, \lambda_{\text {abs }}=263 \mathrm{~nm}$, colourless to pathogens orange-red (red Se)

Incubated at Spherical with a diameter of 50- Chemopreventive against lung

$37^{\circ} \mathrm{C}$ for $24 \mathrm{~h} 80 \mathrm{~nm}, \lambda_{\mathrm{abs}}=560 \mathrm{~nm}$

carcinoma

Incubated for $\lambda_{\text {abs }}=560 \mathrm{~nm}$, size $\sim 153 \mathrm{~nm} \quad$ Antibacterial against Gram positive and 98

5 min and $10 \lambda_{\text {abs }}=580,670 \mathrm{~nm}$, size $\sim 287 \mathrm{~nm}$ Gram negative bacteria

$\min$

$\begin{array}{ccl}5 & \mathrm{Na}_{2} \mathrm{SeO}_{3} & \begin{array}{l}\text { Terminalia } \\ \text { Arjuna leaf extract }\end{array} \\ 6 & \mathrm{H}_{2} \mathrm{SeO}_{4} & \begin{array}{l}\text { L-Cystine } \\ \end{array} \\ 7 & \mathrm{H}_{2} \mathrm{SeO}_{3} & \begin{array}{l}\text { Trigonella foenum-graecum } \mathrm{L} . \\ \text { leaf extract }\end{array} \\ 8 & \mathrm{Na}_{2} \mathrm{SeO}_{3} & \text { Glutathione (GSH) }\end{array}$

$9 \quad \mathrm{Na}_{2} \mathrm{SeO}_{3} \quad$ Glutathione (GSH)

$10 \mathrm{Na}_{2} \mathrm{SeO}_{3} \cdot \quad$ Pseudomonas alcaliphila $5 \mathrm{H}_{2} \mathrm{O}$, cap- (bacteria)

ped with

PVP

$11 \mathrm{H}_{2} \mathrm{SeO}_{3} \quad$ Vitis vinifera extract

$12 \mathrm{Na}_{2} \mathrm{SeO}_{3} \quad$ Ethanol extract of Bee propolis Stirred at RT from Apis mellifera colonies along with ascorbic acid

$13 \mathrm{Na}_{2} \mathrm{SeO}_{3}$ Allium sativum extract for $24 \mathrm{~h}$

Brown to orange colour change $\lambda_{\text {abs }}=265 \mathrm{~nm}$

$D=20 \mathrm{~nm}$, nanospheres with a 5- Anticancer

room tem-
perature for 2-
$8 \mathrm{~h}$

Incubated at Size $=10-80 \mathrm{~nm}, \lambda_{\mathrm{abs}}=390 \mathrm{~nm}$,

$30{ }^{\circ} \mathrm{C}$ for $72 \mathrm{~h}$ dark red, $\lambda_{\mathrm{em}}=595 \mathrm{~nm}$

Heating at Nanospheres $\sim 60 \mathrm{~nm}$, red Se

$105{ }^{\circ} \mathrm{C}$ for $1 \mathrm{~h}$

Incubated at Absorption band $=200-400 \mathrm{~nm}$,

RT for $24 \mathrm{~h}$ red Se, 50-150 $\mathrm{nm}$ oval particles

Instant for- Nanospheres of 40-100 nm size

mation of

SeNPs

Instant for-

mation of

SeNPs in basic

media

Incubated for $\lambda_{\mathrm{abs}}=280 \mathrm{~nm}$, Raman $=254 \mathrm{~cm}^{-1}$ The role of PVP explained in text

$48 \mathrm{~h}$

$(\mathrm{m}$-Se), nanospheres of $40-100 \mathrm{~nm}$

size

Refluxed toge- Nanospheres of 3-18 nm size

Degradation of sunset yellow FCF

Effect against As(III) toxicity

126

Interaction with human serum albumin 109

Breast cancer

88

Prevention of PVC related medical

127

infections

and

128

Cytotoxicity of SeNP coated PVC in rat 6 dermal fibroblasts

Incubated for $7-45 \mathrm{~nm}$, stable up to 2 months Antioxidant

Antioxidant, antimicrobial, anti-

$13 \mathrm{Na}_{2} \mathrm{SeO}_{3} \quad$ Allium satiunm extract

$14 \mathrm{SeO}_{2} \quad$ Lactobacillus brevis

$72 \mathrm{~h}$ until Dark pink colour of solution, $\lambda_{\mathrm{abs}}=$ color change $400 \mathrm{~nm}$

Incubated at -

$37{ }^{\circ} \mathrm{C}$ for $72 \mathrm{~h}$

$15 \mathrm{Na}_{2} \mathrm{SeO}_{3} \quad$ Various cyanobacterial strains $\begin{array}{ll}\text { Incubated at } & \lambda_{\text {abs }}=259-274 \mathrm{~nm} \text {, red spherical Antioxidant } \\ 32{ }^{\circ} \mathrm{C} \text { for } 2-5 & \text { NPs with sizes in the range of 11- }\end{array}$

days $\quad 60 \mathrm{~nm}$ depending upon the strain

$16 \mathrm{Na}_{2} \mathrm{SeO}_{3} \quad$ Moringa oleifera (drumstick) leaf Incubated at $\lambda_{\mathrm{abs}}=299,400 \mathrm{~nm}, \lambda_{\mathrm{em}}=599 \mathrm{~nm}$, Degradation of sunset yellow dye

RT for $24 \mathrm{~h}$ bandgap $=2.3 \mathrm{eV}$ extracts

Mixture of nanospheres and nanorods

Average size $=18.85 \mathrm{~nm}$ (calculated

by Scherrer's equation) and 23-

$35 \mathrm{~nm}$ from TEM

$17 \mathrm{NaHSeO}_{3} \quad$ Crispum (parsley) leaf extracts

Kept over- Orange-red Se

night at room $\lambda_{\mathrm{abs}}=270 \mathrm{~nm}$

temperature Spherical with a maximum num-

ber of particles with a size around

$400 \mathrm{~nm}$ (DLS)

Zeta potential $=-14.2 \mathrm{mV}$

$18 \mathrm{Na}_{2} \mathrm{SeO}_{3} \quad$ Rhizobacterium Azospirillum Incubated at Nanospheres of $50-100 \mathrm{~nm}$ diabrasilense $\mathrm{Sp7}$

$32{ }^{\circ} \mathrm{C}$ for $24 \mathrm{~h}$ meter coated with a thin layer of protein

$19 \mathrm{Na}_{2} \mathrm{SeO}_{3} \quad$ L-Cystine and peptone from Stirring for $36.2 \mathrm{~nm}$ (from XRD) soybean $\quad 10 \mathrm{~h}$ at $25{ }^{\circ} \mathrm{C} \quad 20-50 \mathrm{~nm}$ (TEM)

$20 \mathrm{H}_{2} \mathrm{SeO}_{3} \quad$ Diospyros montana leaf extract

Incubated at $4-16 \mathrm{~nm}$ from TEM and DLS RT for $24 \mathrm{~h}$

$21 \mathrm{Na}_{2} \mathrm{SeO}_{3} \quad$ Mushroom polysaccharide pro- Kept at RT for 100 to $600 \mathrm{~nm}$ in size depending tein complex - stabilising agent, $12 \mathrm{~h}$ with ascorbic acid - reducing agent stirring upon concentration of the stabilising agent

bacterial, antifungal

Anticancer (studies on mice with breast 133 cancer)

and

Anticancer studies on human colon,

breast and hepatic cancers

$-$
Protection against irradiation used nephropathy

Antibacterial activity against Gram (+), 101 Gram (-) bacteria and fungi, anticancer activity against human breast cancer Anticancer activity against human 108 101 breast cancer cells 


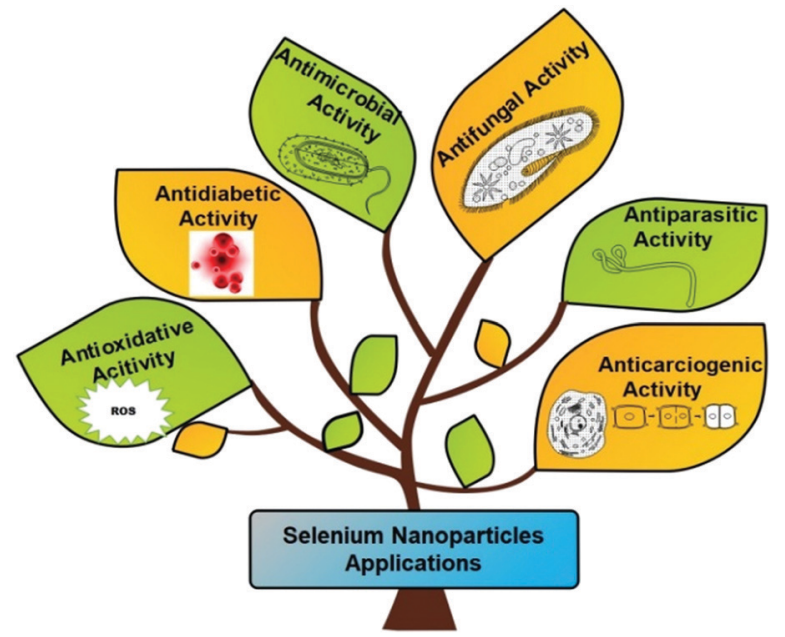

Fig. 5 Pictorial representation of various applications of selenium nanoparticles.

Nano-selenium in the form of nano-medicine offers excellent properties such as antimicrobial, anticancer, antidiabetic, antiparasitic, and antioxidant as shown in Fig. 5. The antioxidative properties of nano-selenium minimize the impact of ROS and free radicals. The higher efficiency of SeNPs displays augmented medicinal effects as antibiotic, antidiabetic, cytotoxic, and chemoprotective medicines in comparison to the traditional therapeutic medicines. ${ }^{138}$ They can also be used as therapeutic and theranostic agents. ${ }^{139}$ It is noteworthy that various studies on SeNPs evidenced reduced toxicity and characteristics of interfacing biomaterials with tissues and cells. SeNPs are biologically active and naturally accessible and take part in numerous oxidoreductive cycles. They also show many regulative outcomes to help the appropriate functioning of plants and living bodies and numerous medical advantages. ${ }^{34,140,141}$ Researchers have shown that SeNPs can be utilized as a cancer preventive agent by controlling the cell damage caused by free radicals, in anticancer therapies, and as antimicrobial agents. These can also be used as an ingredient in nano-biosensor fabrication. The action mechanism of SeNPs can be defined in two ways: (a) disrupting the integrity of the cell membrane through ROS generation and (b) alteration of the DNA sequence of microorganisms by damaging the cell wall and binding to the cell membrane to inhibit the growth of microorganisms. The cycles associated with SeNP preparation can be utilized in wastewater treatment and bioremediation. They can play a significant role in the treatment of heavy metals by combining with them to suppress their poisonous impact. ${ }^{56}$ Based on the abovementioned advantages the next section discusses the various applications of SeNPs in detail.

\subsection{Anti-carcinogenic activity}

Nowadays, selenium nanoparticles are widely being investigated for their anti-cancer activity against breast, lung, kidney, and osteosarcoma cancers based on in vivo and in vitro experiments. ${ }^{88,124,134,142,143}$ However, due to selenium toxicity

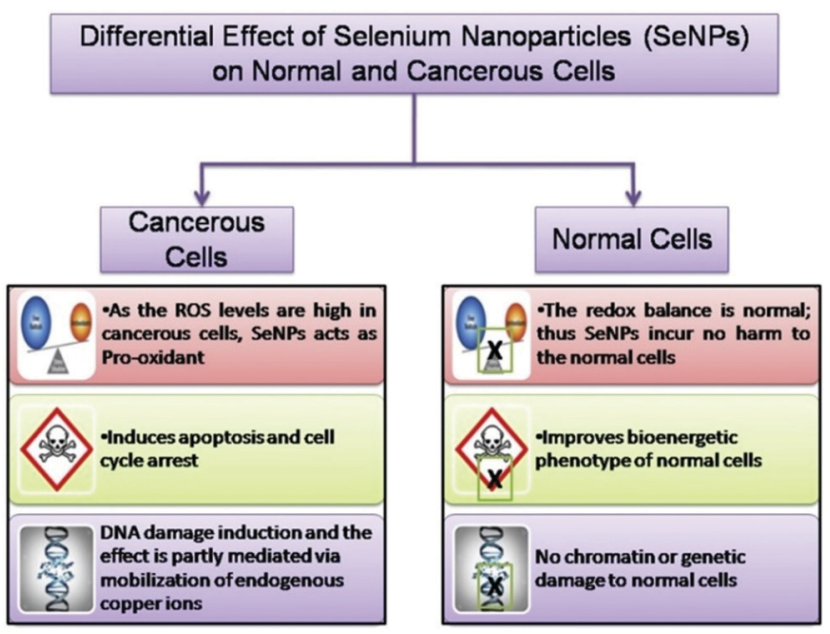

Fig. 6 A schematic of the effect of SeNPs on cancerous and normal cells. Reproduced from ref. 146 (A. Khurana, S. Tekula, M. A. Saifi, P. Venkatesh and C. Godugu, Biomed. Pharmacother., 2019, 111, 802-812), copyright authors 2019, open access Science Elsevier.

and bioavailability elemental selenium and naturally sourced selenium (selenocysteine and selenomethionine) cannot be used in cancer therapies. ${ }^{144}$ Nano-selenium has advantages over other natural sources of selenium because of its size, porosity, and bio-dispersion. Thus, Polyporus umbellatus polysaccharide (PUP) capped SeNPs have been utilized to detect the in vitro anti-proliferation effect with the MTT assay. Particularly, PUP-SeNPs inhibit the cell growth of four types of human cancer: (a) MDA-MB-23 cells causing breast cancer in humans, (b) HepG2 cells responsible for human liver cancer, (c) HeLa cells known for human cervical cancer, and (d) HT 29 for colon cancer. It is shown by researchers that, by using nano-selenium of the above nature, no toxicity to normal human cells such as liver cells (LO2), embryonic kidney cells (293T), and mouse embryonic fibroblast cells (NIH3T3) was observed. ${ }^{145}$ A schematic of the effect of SeNPs on cancerous and normal cells is shown in Fig. $6 .{ }^{146}$

It has been demonstrated by numerous analyses that incorporation of low Se leads to various hazardous diseases. Se acts as a chemopreventive agent when utilized at optimal doses. ${ }^{147,148}$ Selenium has therefore been proposed as a disease therapy agent in combination with chemotherapy and radiation. ${ }^{117}$ The most extreme anticarcinogenic effect of Se has been reported when it is administered at the beginning phase of the disease. ${ }^{149,150}$ The risk of cancer in humans can increase due to the presence of arsenic (As) in drinking water. However, it has been reported that the generation of $\mathrm{As}(\mathrm{III})$ activated ROS can be minimized by use of Terminalia arjuna (TA) leaf extract encapsulated SeNPs, which fortifies As(III)induced cell death and DNA catastrophe. ${ }^{102,151}$ Metastatic breast cancer in a mouse model has been reported to be treated by oral administration of Lactobacillus brevis with SeNPs, which increases interferon generation and delayed hypersensitivity for triggering the immune response. ${ }^{134}$ Therefore, it has been reported by many researchers that if SeNPs are conjugated with 
organic moieties and drugs, they can inhibit accumulation of Se nanoparticles, thereby enhancing the anticancer activity and minimizing the antibiotics' toxic effect. ${ }^{88,143,152-155}$ The nanoconjugates of SeNPs and doxorubicin show enhanced cytotoxic effect against cancer cells by assisting antibiotic cellular uptake. In a study of lactate dehydrogenase activity and cell viability, Yang et al. ${ }^{143}$ found that doxorubicin alone was responsible for destroying $20 \%$ of cancer cells, whereas more than $50 \%$ of cancer cells were destroyed by conjugation of SeNPs and doxorubicin. As an anticancer drug responsible for oxidative stress and DNA cross-linking, cisplatin leads to nephrotoxicity and spermatotoxicity. Interestingly, nephrotoxicity can be reduced using 11-mercapto-1-undecanol functionalized SeNPs by preventing ROS-mediated apoptosis. The antioxidative properties of SeNPs in combination with cisplatin enhance the sperm quality and spermatogenesis. ${ }^{153,154}$ During breast cancer treatment, anastrozole is used to inhibit the growth of aromatase which leads to side effects such as bone fracture and osteoporosis. These can be prevented by conjugating anastrozole with SeNPs. ${ }^{155,156}$ Similarly, SeNPs prepared using highly branched $\beta$-(1-3)-D-glucan obtained from fruiting plants of Auricularia auricula-judae (AF1-Se) showed strong suppression against human breast adenocarcinoma cancer cell lines such as MCF-7, MDA-MB-468, and MDAMB-231. ${ }^{157}$ SeNPs decorated using various polysaccharides extracted from Pleurotus tuberregium (PTR), Ganoderma lucidum (GL), Coriolus versicolor (CV), and Polyporus rhinoceros (PR) showed the highest activity for the gastric cancer cell line AGS. ${ }^{158}$ Induction of cell apoptosis is the key mechanism that plays an important role in the antitumor activities of SeNPs and polysaccharide conjugates. Apoptosis, which is also known as programed cell death, can be described by certain governing properties such as nuclear chromatin condensation, cytoplasm shrinkage, development of apoptotic parts, and membrane dysfunction. ${ }^{159}$ The cellular growth of human lung cancer cell line A549 can be inhibited by utilizing the complex of Arabinogalactans (LAG) and SeNPs. ${ }^{160}$ The human breast cancer can be treated by PUP coated SeNPs through stimulating mitochondria mediated and death receptor mediated apoptotic pathways. The anti-cancer activity of these complexes was regulated by the Bax/Bcl-2 ratio, endorsing cytochrome- $c$ release, enhanced caspase-9, -8, and -3 activities and poly(ADP-ribose) polymerase cleavage. ${ }^{161}$ Therefore, the higher toxicity of SeNPs for cancer cells can be synergistically utilized with anticancer drugs for cancer treatment.

\subsection{Antioxidant activity}

ROS and reactive nitrogen species (RNS) free radicals are generally generated in the human body during several physicochemical and biochemical reactions. The higher amounts of intermediate complexes such as superoxide and hydrogen peroxide produced during these reactions are responsible for cellular damage, leading to generation of lethal diseases. Therefore, antioxidative compounds are utilized to suppress the creation as well as scavenging of these free radicals. ${ }^{162,163}$ The surface of Se nanoparticles decorated with various organic

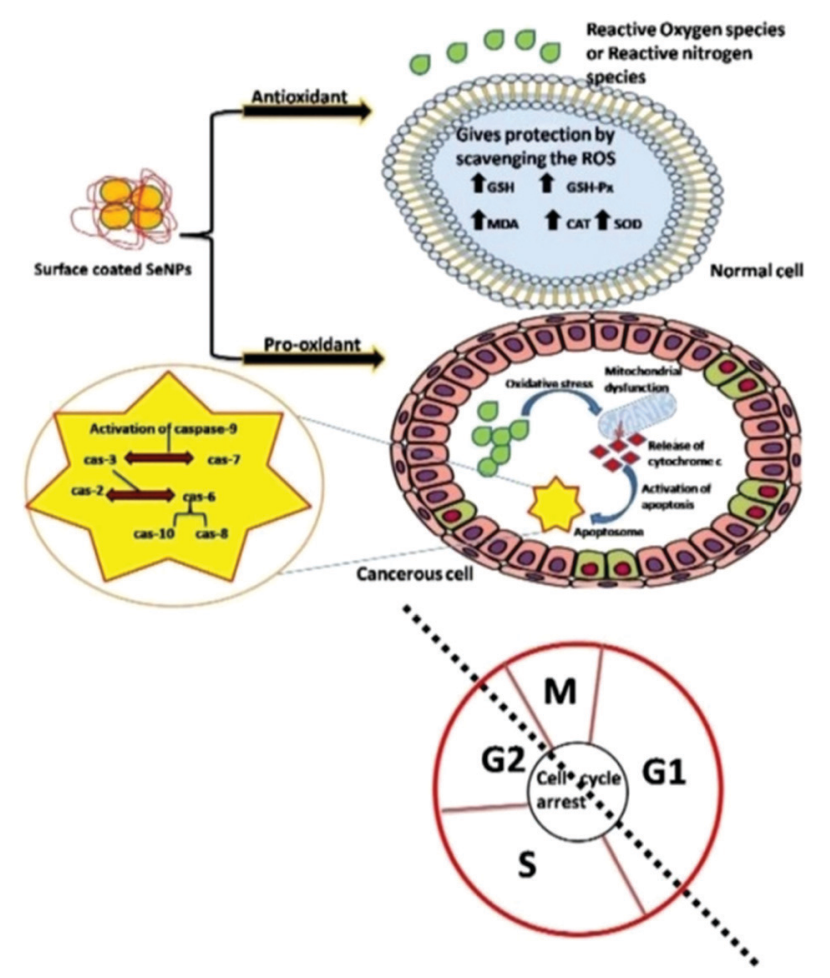

Fig. 7 A systematic representation of the action mechanism by surface decorated Se NPs on various cells as an antioxidant and a pro-oxidant. Reproduced from ref. 164 with permission from Science Elsevier, copyright 2020.

molecules and plant extracts act as both antioxidants and pro-oxidants on different cells of the human body and their action mechanism is shown in Fig. $7 .{ }^{164}$ Battin et al. ${ }^{165}$ reported that selenium nanoparticles can play an important role in minimizing the free radical concentration to prevent the oxidative damage of DNA in both in vivo and in vitro experimental conditions. It has also been documented that selenoprotein is a key source of selenium and produces vital antioxidants such as deiodinase, thioredoxin reductase, and glutathione peroxidase. ${ }^{166}$ In an investigation, Zhang et al. ${ }^{167}$ showed that sodium selenium inhibited the growth of Candida utilis by improving the excretion and biosynthesis of glutathione. Similarly, chitosan functionalized SeNPs showed enhanced glutathione peroxidase and anticipated lipofuscin development in mice. ${ }^{168}$ Additionally, $\mathrm{ABTS}^{\circ}+$ and superoxide anion radical can be scavenged by utilizing SeNPs in combination with Cordyceps sinensis exopolysaccharide. ${ }^{145}$ The plant-based synthesis of selenium nanoparticles demonstrated antioxidative activity through ABTS and DPPH assays. ${ }^{169}$ Further, the Kong group $^{170}$ presented the enhanced antioxidative activity of gum-arabic functionalized SeNPs (GA-SeNPs) for scavenging hydroxyl radicals and the DPPH assay test. In an investigation, selenium nanoparticles acted as a hepatoprotective component against acetaminophen accelerated hepatotoxicity by refining liver capacity and restraining oxidative stress in rats. In another study Kokila et al. ${ }^{101}$ demonstrated the conceivable antioxidative properties of SeNPs. It is known from the literature that the 
shape and size of nanoparticles can play a key role in such studies. For example, hollow spherical selenium nanoparticles have shown antioxidative properties. ${ }^{32,36,37}$ Thus, plant based SeNPs show better prevention against ROS mediated oxidative stress induced diseases.

\subsection{Antidiabetic activity}

The high amount of glucose in our body due to the absence of enough insulin creation or inadequate usage of insulin leads to chronic diseases like diabetes. The insulin chemical is responsible for maintaining the blood sugar level. Diabetes negatively impacts people of all age groups. Several researchers have reported the use of selenium nanoparticles in the treatment of diabetes because of its effective controlling ability to regulate the blood sugar level. ${ }^{171}$ The long-term effects of diabetes can damage large and small blood vessels, causing a problem in the functioning of various human organs. Diabetes leads to the generation of various diseases in the heart, legs, brain, eyes, kidneys, skin, digestive system, oral health, and immune system as shown in Fig. 8. Deng et al. ${ }^{172}$ reported that Se nanoparticles loaded with insulin (INS-SeNPs) can be delivered orally to treat diabetes in mice. In their study the researchers stated that the insulin was released in the blood in a controllable manner and showed excellent stability in digestive foods. The Liu group ${ }^{173}$ examined the enhanced antidiabetic activity of Catathelesma ventricosum polysaccharides (CVPs) coated Se nanoparticles in streptozocin (STZ) induced diabetic mice. Similarly, the effect of SeNPs in combination with insulin was investigated by Quraishy et al. ${ }^{174}$ to enhance the activity of hyperglycemia and hyperlipidemia in STZ induced diabetes in mice. At a concentration of $2.0 \mathrm{mg} \mathrm{kg}^{-1}$ body weight, chitosan stabilized SeNPs resulted in improved antidiabetic activity. ${ }^{175}$ Furthermore, phytomedicines are proven candidates to combat diabetes in an effective way. ${ }^{176}$ Therefore, Deng et al. ${ }^{177}$ demonstrated that extracts of mulberry leaf and Pueraria lobata (MPE)

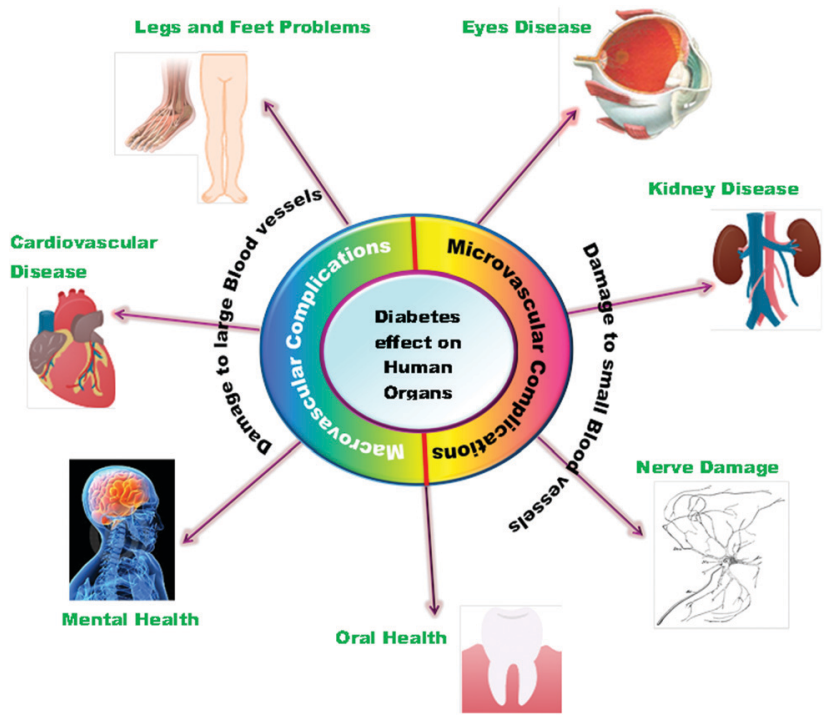

Fig. 8 Effect of diabetes on various human organs.

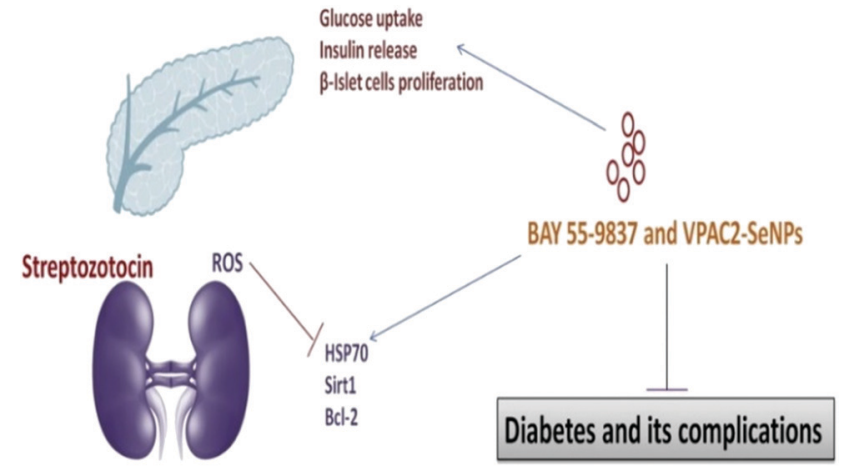

Fig. 9 The effect of SeNPs on diabetic cells. Reproduced from ref. 146 (A. Khurana, S. Tekula, M. A. Saifi, P. Venkatesh and C. Godugu, Biomed. Pharmacother., 2019, 111, 802-812), copyright authors 2019, open access Science Elsevier.

(phytomedicines) coated SeNPs exerting a hypoglycemic effect can cure diabetes mellitus. The plasma associated selenium demonstrated a positive effect on prevalent and incident diabetes by redox regulation and signaling of insulin pathways. ${ }^{178}$ Therefore, selenium nanoparticles functionalized with various moieties are expected to play a crucial role in treating different types of diabetes. A schematic of the effect of SeNPs on various diabetic cells is shown in Fig. 9. ${ }^{146}$

\subsection{Antimicrobial activity}

Living beings are susceptible to microbial infections leading to numerous diseases causing great health concerns. Nowadays, most of the pathogenic organisms have become drug-resistant because of the constant utilization of a wide range of antibiotics. Particularly, multidrug-resistant microorganisms and fungi are profoundly becoming irresistible as they have procured protection from practically all the accessible antimicrobial drugs. ${ }^{179-181}$ Therefore, anti-infection agents are developed for the treatment of these irresistible diseases. There are a variety of metal nanoparticles as well as metal oxides and their combinations which have been documented as potential antimicrobial agents. SeNPs have also found tremendous scope in biomedical applications as an antimicrobial agent to protect implanted clinical gadgets from bacteria. Tran et al. ${ }^{41}$ incorporated SeNPs by an in situ method into regular polymers such as polyvinyl chloride, polyurethane, and silicon, which are generally used in biomedical devices. They observed that the antibacterial performance was directly linked with the concentration of selenium as the coating material in combination with different polymers. Their findings stated that nanoselenium coated polymers essentially can hinder Staphylococcus aureus (S. aureus) growth, in contrast to uncoated polymers. Additionally, they discovered that SeNP-covered PVC shows more prominent antibacterial effects compared to commercially available Ag-covered PVC. ${ }^{41}$ Generally, biofilm development on the surfaces of clinical gadgets by microbes is difficult to treat. Thus, SeNPs act as a suppressing agent for biofilm formation. ${ }^{34,182-184}$ Wang et al. ${ }^{42}$ reported biogenic SeNPs utilizing Bacillus licheniformis JS2 to suppress bacterial 
(S. aureus) adherence, biofilm development, and microcolony formation to various polymer surfaces. These outcomes have possible incentive for application as antibacterial covering prostheses against $S$. aureus and other clinical gadgets against nosocomial infections. ${ }^{183}$ Shakibaie et al. ${ }^{26}$ studied various biofilm forming microbes such as $S$. aureus, Proteus mirabilis, (P. mirabilis), and Pseudomonas aeruginosa ( $P$. aeruginosa) to check the viability of biogenic SeNPs-Bacillus sp. MSh-1, having spherical morphology with the dimension range of 80-220 nm. For comparison purposes they incubated the biofilm formation assay with both SeNPs and $\mathrm{SeO}_{2}$ with microbes. In both the cases, they observed no significant decrease in the biofilm formation; however, due to the lower toxicity of SeNPs they were preferred over $\mathrm{SeO}_{2}$. It was believed that SeNPs show antibacterial activity due to oxidative stress. ${ }^{185}$ Huang et al. ${ }^{186}$ reported a new inorganic antibacterial agent based on quercetin (Qu) and acetylcholine (Ach) functionalized SeNPs (QuAch@SeNPs), which demonstrated improved antimicrobial activity against multidrug-resistant superbugs (MDRs) in contrast to individual Qu@SeNPs and Ach@SeNPs. They observed that when Qu-Ach@SeNPs adhered to the bacterial cell surface, causing disruption of the cytoplasmic membrane, the growth of bacterial cell methicillin resistant $S$. aureus (MRSA) was inhibited and the DNA structure was damaged by antibacterial action as shown in Fig. 10. ${ }^{186}$

In a separate study researchers ${ }^{40}$ also found that an in vitro study involving SeNPs emphatically suppressed the growth of S. aureus (60 times higher) at different doses such as 7.8, 15.5, and $31 \mu \mathrm{g} \mathrm{mL} \mathrm{m}^{-1}$ for time periods of 3,4 , and $5 \mathrm{~h}$, respectively. However, this study was found unsuitable in microbiology in terms of an effective antimicrobial agent. Therefore, to overcome these issues Mittal et al. ${ }^{187}$ combined selenium and silver nanoparticles to enhance the antimicrobial activity. Here, AgSeNPs having a size range of $30-35 \mathrm{~nm}$ were synthesized utilizing bioactive gallic acid and quercetin (QC). The antimicrobial activity of the composite of Qu-gallic acid@Ag-SeNPs was found to be superior to both silver nitrate and sodium selenite against Escherichia coli (E. coli) and Bacillus subtilis (B. subtilis) on agar plates. They also found comparable results of the nanocomposite with an antimicrobial agent, chloramphenicol, for an equivalent dose of $50 \mu \mathrm{g} \mathrm{mL}{ }^{-1}$. Here, the

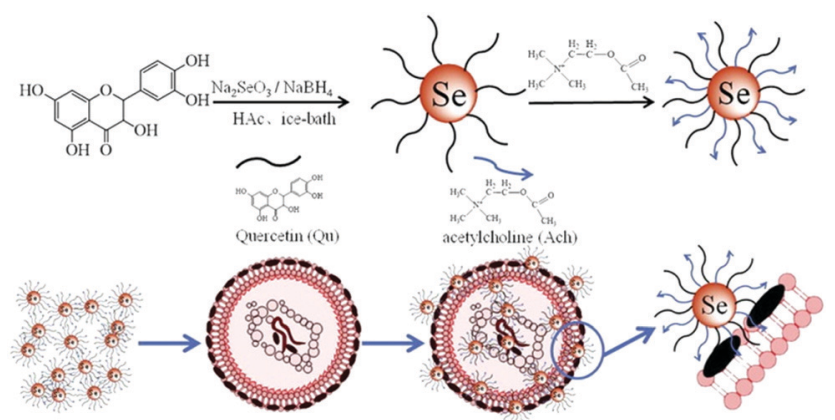

Fig. 10 A schematic representation of the synthesis of Qu-Ach SeNPs and their antibacterial action. Reproduced from ref. 186 with permission from Science Elsevier, copyright 2016. authors described the antimicrobial mechanism in two ways: in the first assumption, the nanoparticles adhere to the bacterial cell wall, where silver NPs are released and destroy the bacterial cells; in the second assumption, the interconnectivity of AgNPs with DNA and bacterial protein and more activity for sulfur and phosphorus compounds leads to destruction of these compounds. Menon et al. ${ }^{188}$ reported biosynthesized SeNPs from $Z$. officinale with spherical morphology and a 100-150 nm size range. They examined the antimicrobial activity of the SeNPs against five microbial species such as E. coli, Klebsiella sp., Pseudomonas sp., S. aureus, and Proteus sp. The Proteus sp. bacterial growth was effectively inhibited by SeNPs at a concentration of $250 \mu \mathrm{g} \mathrm{mL}^{-1}$. Generally, SeNPs have size and concentration dependent effects against various microorganisms. ${ }^{189}$ Further, selenium and tellurium nanoparticles exhibit antimicrobial activity and destruction of biofilm formation. These nanoparticles were effective on inhibiting the growth of E. coli JM109, Pseudomonas aeruginosa PAO1, and $S$. aureus ATCC 25923. ${ }^{190}$ Consequently, SeNPs can be utilized as an effective antimicrobial agent in pharmaceutical applications.

\subsection{Antifungal activity}

SeNPs acquire antifungal properties for various biological applications. To name a few, SeNPs can be used for the treatment of fungal infections in immunity compromised patients, improvement in probiotic concentration, and fabrication of antifungal and antibacterial cloths for protecting skin from $S$. aureus and Tinea pedis infections ${ }^{191}$ as shown in Fig. 11. To prove this, Yip et al. ${ }^{192}$ demonstrated that nano-Se modified with biogenic polysaccharide-protein (PSP) complexes collected from Pleurotus tuber-regium deposited on a fabric was effective in inhibiting the growth of S. aureus and Trichophyton rubrum bacteria. Similarly, Shakibaie et al. ${ }^{193}$ examined the antifungal activity of Bacillus sp. Msh-1 functionalized SeNPs against Aspergillus fumigatus (pulmonary infection) and Candida albicans (skin infection). Shahverdi et $a .^{24}$ reported SeNPs prepared from Klebsiella pneumoniae to treat antifungal infections from Malassezia sympodialis, Malassezia furfur, and Aspergillus terreus in the concentration range from 10 to $260 \mu \mathrm{g} \mathrm{mL} \mathrm{m}^{-1}$. Particularly, SeNPs can provide antifungal activity in patients having less immunity against nystatin-immune Candida sp. ${ }^{194}$

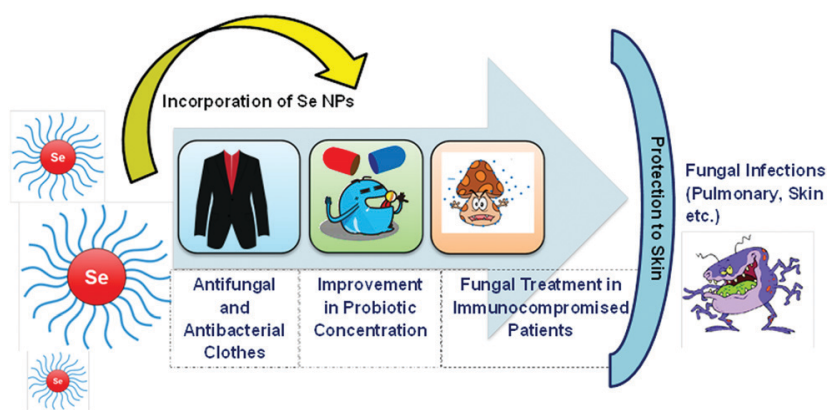

Fig. 11 A schematic of the utilization of SeNPs against various fungal infections. 
and a more constructive therapy to encounter intrusive aspergillosis in comparison to the amphotericin B drug. ${ }^{193}$ However, conflicting results have been obtained by the Kazempour group on SeNPs prepared from Klebsiella pneumoniae. They found that SeNPs lack in treating the post-antifungal effect of Aspergillus niger (A. niger) and Candida albicans (C. albicans) and a lower concentration of Se stimulated the growth of $A$. niger. It was assumed that the reason behind this mechanism is 'the physiological impact of selenium on specific proteins in A. niger. The outcomes may have direct ramifications on dermatitis caused by A. niger or C. albicans. These pathogenic microorganisms can regrow on the skin by exposing to SeNPs' environment. Generally, the post-antifungal effect (PAE) is a vital pharmacodynamic boundary which helps in setting up measurement regimes by demonstrating inhibition of antimicrobe development after exposing microorganisms to antimicrobial agents for a short period of time. ${ }^{195-197}$

\subsection{Antiparasitic activity}

In the past few years, different research groups have made aggressive efforts on exploring the antiparasitic properties of selenium nanoparticles. ${ }^{25,198,199}$ Various types of parasitic diseases and their effects on human organs are shown in Fig. 12. By in vivo and in vitro studies, it was found that biosynthesized SeNPs from Bacillus sp. Msh-1 can be used in the treatment of Leishmania major parasites such as Promastigote and Amastigote. ${ }^{25}$ Similarly, in vitro experiments of leishmanicidal activity to combat Leishmania tropica (L. tropica) ${ }^{200}$ and Leishmania infantum (L. infantum) ${ }^{199}$ have been reported by use of Bacillus sp. Msh-1 functionalized SeNPs. The gel electrophoresis method has been reported for in vitro investigation of selenium nanoparticles to understand the time-dependent decrease in Promastigote multiplication due to the presence of DNA fragmentation. ${ }^{201}$ Biosynthesized SeNPs with a size range of 80-220 nm showed a strong scolicidal activity against parasitic infections (Cystic echinococcus) through an in vitro study. ${ }^{202} \mathrm{~A}$ comparable time-dependent cytotoxic outcome was also

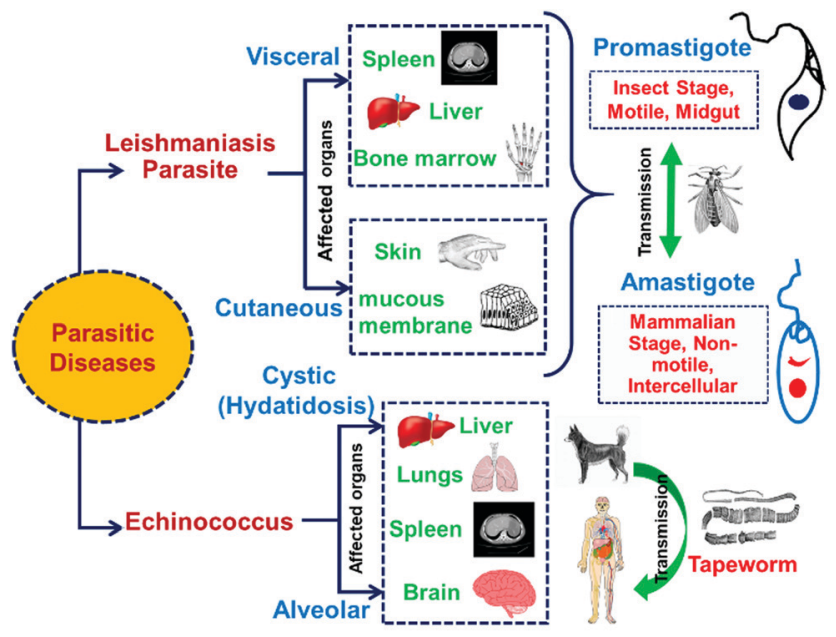

Fig. 12 Types of parasitic diseases that can be treated by SeNPs. illustrated against intracellular amastigotes. A study on male mice $(\mathrm{BALB} / \mathrm{c})$ infected with Leishmania major showed a reduced progression in lesion growth by ejaculation of SeNPs. Soflaei et al. ${ }^{199}$ reported the antileishmanial properties of SeNPs in both Promastigotes and Amastigotes of L. infantum in contrast to $\mathrm{SeO}_{2}$. The study demonstrated that SeNPs showed improved performance and less cytotoxicity than $\mathrm{SeO}_{2}$ in a time and dose dependent antileishmanial activity. In another study, Mahmoudvand et al. ${ }^{200}$ reported that SeNPs with a particular size range were effective in inhibiting the resistance of Meglumine antimoniate (MA) and MA-sensitive L. tropica in vitro. Essentially, these outcomes indicated suppression of promastigote depending on the dose, decreased intramacrophage amastigote feasibility in the two strains, and outstanding impact on prophylaxis treatment. Additionally, SeNPs exhibited improved antileishmanicidal activity in conjugation with MA, in contrast to SeNPs or MA alone. ${ }^{138}$

Hence, it is concluded that biosynthesized SeNPs with a particular particle size range shows higher resistant against Leishmania parasitic diseases.

\subsection{Other biological applications}

Besides the antibacterial properties, SeNPs have also been utilized as wound dressing materials. Biswas et al. ${ }^{203}$ confirmed the antibacterial properties of permeable chitosan/polyvinyl alcohol (PVA) (CS) in situ mediated Se nanorods compared to $\mathrm{Ag}$ nanoparticles (CS-Ag). Both the nanoparticles $\mathrm{CS}-\mathrm{Se}$ and CS-Ag exhibited antibacterial activity against Gram-negative (E. coli), Gram-positive (S. aureus), and methicillin-resistant $S$. aureus (MRSA). The slow release of $\mathrm{Ag}$ and Se nanoparticles was dependent on the delivery medium utilized during treatment. From the study it was found that CS-Se scaffolds are less cytotoxic toward mammalian cells when compared with the CSAg system. Similarly, Ramya et al. ${ }^{204}$ explored the in vivo impact of biosynthesized Se nanoparticles stabilized with Streptomyces minutiscleroticus M10A62 (spherical size) on Swiss albino mice for wound treatment. The obtained results demonstrated that a high dose of SeNPs (10\%) ointment effectively and quickly healed the wound.

Selenium has been additionally found to have a chemoprotective effect against chemotherapy-prompted toxicity. Bhattacharjee et $a .^{205}$ examined Swiss albino mice for treating cyclophosphamide (CP)-prompted hepatotoxicity and genotoxicity by utilizing SeNPs. In the mice, SeNPs switched or potentially enhanced the effects of CP-instigated toxicity: rebuilding of cell reinforcement protein activity, decrease in reactive oxygen species, glutathione levels, and chromosomal variations in bone marrow, and DNA damage. ${ }^{205}$ Further, in another study they found that SeNPs also possess chemosensitizing and chemoprotective activities. After injecting SeNP adjuvant with cyclophosphamide into Ehrlich's ascites carcinoma (EAC) containing Swiss albino mice, the following changes were observed: a critical decrease in practical tumor cell count, packed cell and tumor volume, while an increase in tumorbearing hosts' survivability. ${ }^{206}$ Gao et al. ${ }^{207}$ reported SeNPs as an effective chemotherapy protective agent against 
chemotherapy-prompted toxicity of irinotecan by both in vivo and in vitro studies.

In another study, it was found that the red-allotrope of selenium nanoparticles (rSeNPs) show higher cytotoxicity towards head and neck squamous cell carcinoma (HNSCC) than human dermal fibroblast (HDF) cells, which resulted in cell proliferation. ${ }^{208}$ Additionally, SeNPs can be used as a potential candidate in chemoradiotherapy and radiation sensitizer. Generally, to treat cancer cells external radiation therapy has been utilized broadly. However, these unpredictable radiations can damage adjacent healthy cells. To overcome this unavoidable impact, chemo-radiotherapy can be utilized with a radioactive seed to deliver enhanced, efficient and precise radiation. Based on this concept, Bhattacharjee et al. ${ }^{205}$ performed a combined in vivo and in vitro experiment by utilizing folic acid capped SeNPs (FA-SeNPs) in conjugation with radioactive ${ }^{125} \mathrm{I}$ seeds to impart enhanced anticancer activity. In comparison with individual treatment, the combination of (FA-SeNPs) and ${ }^{125}$ I seeds demonstrated a better in vivo antitumor effect and lower cytotoxicity in MCF-7 infected mice. Yu et $a .^{209}$ reported that Se nanoparticles in combination with radiation reduces the damage to nearby tissues and enhances the carcinogenic cell affectability to the harmful impacts of illumination on MCF-7 breast cancer cells by in vitro studies. Karami et al. ${ }^{106}$ reported the radioprotective effects of SeNPs and sodium selenite on gamma radiation $(0,2$, and $8 \mathrm{~Gy})$ incited nephropathy in mice for 14 days. They concurrently treated the mice by administrating SeNPs (spherical and $20-50 \mathrm{~nm}$ in size) or sodium selenite $\left(0.1 \mathrm{mg} \mathrm{kg}^{-1}\right)$. After 48 hour exposure they found that SeNPs were more viable than sodium selenite on controlling the factors responsible for nephropathy.

\section{Conclusion and future prospects}

Selenium is an essential micronutrient required for proper functioning of biological and metabolic mechanism within the human body. Deficiency of selenium leads to the generation of several harmful disorders such as cancer, neurological, muscular, immune, etc. Generally, selenium can be depicted within a very narrow concentration range due to its deficiency, physiological effect, and toxic doses. At optimal doses Se acts as an antioxidant, whereas at higher doses it shows pro-oxidant activity. To overcome this issue, a precisely controlled dosage of Se is generally suggested. Selenium has various health advantages because of its bioavailability in the form of selenoproteins as well as lower molecular weight. Various selenoproteins (Se1P, Se1F, Se1S, Se1M), thioredoxin reductases, and glutathione peroxidases show redox activity and control redox reactions in cells. However, concerns related to selenium toxicity lead researchers to focus on nano-selenium. The present review emphasized the various methods used for the synthesis of selenium nanoparticles mainly focused on biogenic methods and their biological applications. Biogenic methods have more advantages over chemical reduction methods due to their higher biocompatibility, bioactivity, and lower cytotoxicity. Biological synthesis is economical, eco-friendly and safe unlike chemical reduction techniques requiring hazardous chemicals, high temperatures and acidic $\mathrm{pH}$. Use of plant extracts, however, is more favourable in comparison to the bacterial path as it eliminates the tedious procedures and cost for maintaining the cell cultures.

SeNPs have various biological applications due to their excellent properties. SeNPs play a key role in various biological applications due to their association with various moieties such as selenoproteins, selenocysteine, selenomethionine, etc. Several studies showed that SeNPs are excellent in combating fatal diseases like cancer, diabetes, Alzheimer's, drug-induced toxicity, etc. However, nanoparticle induced toxicity is still a major concern for researchers. The authors concluded from the literature that mostly SeNPs ranging from 50 to $200 \mathrm{~nm}$ were effective for their use as a therapeutic agent in cancer treatment and antioxidant and antimicrobial applications.

The near future potential of selenium nanoparticles can be considered in pharmaceutical applications and nutritional supplements. Biogenic SeNPs can be explored for their use as anti-TB and anti-viral agents, drug delivery systems, and as catalysts. More precise clinical trials are required for checking the viability of SeNPs on human health. Extensive research is required to develop less toxic and low cost synthesis methods and to understand the role of nano-selenium in cancer therapy, chemotherapy, and radiation therapy to modulate their efficiency and cytotoxicity. Particularly, the development of new nanoparticle delivery systems can provide substantial dietary and therapeutic potential by offering transport of selenium in organs which can modify the physiochemical properties of the nanoparticles, and higher stability within the gastrointestinal tract by permitting precise release of selenium.

\section{Author contributions}

All the authors contributed equally.

\section{Conflicts of interest}

There are no conflicts to declare.

\section{Acknowledgements}

The authors thank the Vice-Chancellor, Defence Institute of Advanced Technology (DIAT), Girinagar, Pune for encouragement and permission. PKK thanks DMSRDE, DRDO India for support.

\section{References}

1 M. Zhu, G. Niu and J. Tang, J. Mater. Chem. C, 2019, 7, 2199-2206.

2 A. A. Jadhav and P. K. Khanna, RSC Adv., 2015, 5, 44756-44763. 
3 U. K. EGVM, Revised Review of Selenium, United Kingdom Expert Gr. Vitam. Miner. (EVM/99/17. REVISEDAUG2002).

4 Joint FAO/WHO Consultation on Preparation and Use of Food-Based Dietary Guidelines (1995: Nicosia C). and World Health Organization, Geneva, 1998, p. 880.

5 N. I. Krinsky, G. R. Beecher, R. F. Burk, A. C. Chan, J. W. Erdman, R. A. Jacob, I. Jialal, L. N. Kolonel, J. R. Marshall and P. R. L. Taylor Mayne, Dietary reference intakes for vitamin C, vitamin E, selenium, and carotenoids, The National Academies Press Washington, DC, USA, 2000.

6 J. F. Ramos and T. J. Webster, Int. J. Nanomed., 2012, 7, 3907-3914.

7 J. E. Spallholz, Free Radic. Biol. Med., 1994, 17, 45-64.

8 F. Sieber, J.-P. Daziano, W. H. H. Günther, M. Krieg, K. Miyagi, R. W. Sampson, M. D. Ostrowski, G. S. Anderson, I. Tsujino and R. J. Bula, Phosphorus Sulfur Silicon Relat. Elem., 2005, 180, 647-657.

9 F. Islam, S. Zia, I. Sayeed, K. S. Zafar and A. S. Ahmad, Biol. Trace Elem. Res., 2002, 90, 203-214.

10 K. Venardos, G. Harrison, J. Headrick and A. Perkins, Redox Rep., 2004, 9, 317-320.

11 K. Venardos, G. Harrison, J. Headrick and A. Perkins, J. Trace Elem. Med. Biol., 2004, 18, 81-88.

12 J. Vanderlelie, K. Venardos and A. V. Perkins, Reproduction, 2004, 128, 635-641.

13 S. V. Gudkov, G. A. Shafeev, A. P. Glinushkin, A. V. Shkirin, E. V. Barmina, I. I. Rakov, A. V. Simakin, A. V. Kislov, M. E. Astashev and V. A. Vodeneev, ACS Omega, 2020, 5, 17767-17774.

14 D. Huang, B. Ou and R. L. Prior, J. Agric. Food Chem., 2005, 53, 1841-1856.

15 R. Pillai, J. H. Uyehara-Lock and F. P. Bellinger, IUBMB Life, 2014, 66, 229-239.

16 M. P. Rayman, Lancet, 2000, 356, 233-241.

17 M. P. Look, J. K. Rockstroh, G. S. Rao, K. A. Kreuzer, S. Barton, H. Lemoch, T. Sudhop, J. Hoch, K. Stockinger and U. Spengler, Eur. J. Clin. Nutr., 1997, 51, 266-272.

18 M. A. Ansari, A. S. Ahmad, M. Ahmad, S. Salim, S. Yousuf, T. Ishrat and F. Islam, Biol. Trace Elem. Res., 2004, 101, 73-86.

19 K. S. Zafar, A. Siddiqui, I. Sayeed, M. Ahmad, S. Salim and F. Islam, J. Neurochem., 2003, 84, 438-446.

20 M. Vahdati and T. Tohidi Moghadam, Sci. Rep., 2020, 10, 510.

21 H. Forootanfar, M. Adeli-Sardou, M. Nikkhoo, M. Mehrabani, B. Amir-Heidari, A. R. Shahverdi and M. Shakibaie, J. Trace Elem. Med. Biol., 2014, 28, 75-79.

22 B. Yu, Y. Zhang, W. Zheng, C. Fan and T. Chen, Inorg. Chem., 2012, 51, 8956-8963.

23 H. Hariharan, N. Al-Harbi, P. Karuppiah and S. Rajaram, Chalcogenide Lett., 2012, 9, 509-515.

24 A. R. Shahverdi, A. Fakhimi, G. Mosavat, P. JafariFesharaki, S. Rezaie and S. M. Rezayat, World Appl. Sci. J., 2010, 10, 918-922.

25 N. Beheshti, S. Soflaei, M. Shakibaie, M. H. Yazdi, F. Ghaffarifar, A. Dalimi and A. R. Shahverdi, J. Trace Elem. Med. Biol., 2013, 27, 203-207.
26 M. Shakibaie, H. Forootanfar, Y. Golkari, T. MohammadiKhorsand and M. R. Shakibaie, J. Trace Elem. Med. Biol., 2015, 29, 235-241.

27 W. Cong, R. Bai, Y.-F. Li, L. Wang and C. Chen, ACS Appl. Mater. Interfaces, 2019, 11, 34725-34735.

28 J. A. Johnson, M.-L. Saboungi, P. Thiyagarajan, R. Csencsits and D. Meisel, J. Phys. Chem. B, 1999, 103, 59-63.

29 O. Vidal, B. Goffé and N. Arndt, Nat. Geosci., 2013, 6, 894-896.

30 R. Jain, G. Gonzalez-Gil, V. Singh, E. D. Van Hullebusch, F. Farges and P. N. L. Lens, Nanobiotechnology, 2014, 10, 365-394.

31 M. Panahi-Kalamuei, M. Salavati-Niasari and S. M. Hosseinpour-Mashkani, J. Alloys Compd., 2014, 617, 627-632.

32 J.-S. Zhang, X.-Y. Gao, L.-D. Zhang and Y.-P. Bao, BioFactors, 2001, 15, 27-38.

33 J. Zhang, X. Wang and T. Xu, Toxicol. Sci., 2008, 101, 22-31.

34 S. Skalickova, V. Milosavljevic, K. Cihalova, P. Horky, L. Richtera and V. Adam, Nutrition, 2017, 33, 83-90.

35 J. Zhang, H. Wang, X. Yan and L. Zhang, Life Sci., 2005, 76, 1099-1109.

36 X. Gao, J. Zhang and L. Zhang, Adv. Mater., 2002, 14, 290-293.

37 H. Wang, J. Zhang and H. Yu, Free Radic. Biol. Med., 2007, 42, 1524-1533.

38 T. Ikemoto, T. Kunito, H. Tanaka, N. Baba, N. Miyazaki and S. Tanabe, Arch. Environ. Contam. Toxicol., 2004, 47, 402-413.

39 B. Huang, J. Zhang, J. Hou and C. Chen, Free Radic. Biol. Med., 2003, 35, 805-813.

40 P. A. Tran and T. J. Webster, Int. J. Nanomed., 2011, 6, 1553.

41 P. A. Tran and T. J. Webster, Nanotechnology, 2013, 24, 155101.

42 Q. Wang and T. J. Webster, J. Biomed. Mater. Res., Part A, 2012, 100, 3205-3210.

43 B. T. Mayers, K. Liu, D. Sunderland and Y. Xia, Chem. Mater., 2003, 15, 3852-3858.

44 B. Yu, P. You, M. Song, Y. Zhou, F. Yu and W. Zheng, New J. Chem., 2016, 40, 1118-1123.

45 A. H. Shar, M. N. Lakhan, J. Wang, M. Ahmed, K. T. Alali, R. Ahmed, I. Ali and A. Q. Dayo, Dig. J. Nanomater. Biostruct., 2019, 14, 867-872.

46 Y. Zhu, Y. Qian, H. Huang and M. Zhang, Mater. Lett., 1996, 28, 119-122.

47 M. Quintana, E. Haro-Poniatowski, J. Morales and N. Batina, Appl. Surf. Sci., 2002, 195, 175-186.

48 T. Vasileiadis, V. Dracopoulos, M. Kollia, L. Sygellou and S. N. Yannopoulos, J. Nanopart. Res., 2019, 21, 1-8.

49 B. Gates, Y. Yin and Y. Xia, J. Am. Chem. Soc., 2000, 122, 12582-12583.

50 B. Mayers and Y. Xia, Adv. Mater., 2002, 14, 279-282.

51 X.-L. Li, G.-H. Cao, C.-M. Feng and Y.-D. Li, J. Mater. Chem., 2004, 14, 244-247.

52 A. A. Jadhav, P. V. More and P. K. Khanna, RSC Adv., 2015, 5, 76733-76742. 
53 P. K. Khanna, A. Jadhav and P. V. More, J. Nanosci. Nanotechnol., 2020, 20, 2946-2954.

54 P. K. Khanna, P. More, B. G. Bharate and A. K. Vishwanath, J. Lumin., 2010, 130, 18-23.

55 V. Singh, Priyanka, P. V. More, E. Hemmer, Y. K. Mishra and P. K. Khanna, Mater. Adv., 2021, 2, 1204-1228.

56 A. Kumar and K. S. Prasad, J. Biotechnol., 2021, 325, 152-163.

57 M. Ikram, B. Javed, N. I. Raja and Z. U. R. Mashwani, Int. J. Nanomed., 2021, 16, 249-268.

58 T. Nie, H. Wu, K.-H. Wong and T. Chen, J. Mater. Chem. B, 2016, 4, 2351-2358.

59 H. Fernández-Llamosas, L. Castro, M. L. Blázquez, E. Díaz and M. Carmona, Microb. Cell Fact., 2016, 15, 1-10.

60 S. Shirsat, A. Kadam, M. Naushad and R. S. Mane, RSC Adv., 2015, 5, 92799-92811.

61 C. Kim, J. Hong and J.-W. Park, Polymers, 2019, 11, 1052.

62 Y.-Y. Xia, Mater. Lett., 2007, 61, 4321-4324.

63 Y. Zhan, Y. Liu, H. Zu, Y. Guo, S. Wu, H. Yang, Z. Liu, B. Lei, J. Zhuang, X. Zhang, D. Huang and C. Hu, Nanoscale, 2018, 10, 5997-6004.

64 M. A. El-Ghazaly, N. Fadel, E. Rashed, A. El-Batal and S. A. Kenawy, Can. J. Physiol. Pharmacol., 2017, 95, 101-110.

65 P. A. Tran, N. O’Brien-Simpson, E. C. Reynolds, N. Pantarat, D. P. Biswas and A. J. O'Connor, Nanotechnology, 2016, 27, 45101.

66 A. Khalid, P. A. Tran, R. Norello, D. A. Simpson, A. J. O'Connor and S. Tomljenovic-Hanic, Nanoscale, 2016, 8, 3376-3385.

67 S. Boroumand, M. Safari, E. Shaabani, M. Shirzad and R. Faridi-Majidi, Mater. Res. Express, 2019, 6, $0850 \mathrm{~d} 8$.

68 C. P. Shah, M. Kumar, K. K. Pushpa and P. N. Bajaj, Cryst. Growth Des., 2008, 8, 4159-4164.

69 Y. Zhang, J. Wang and L. Zhang, Langmuir, 2010, 26, 17617-17623.

70 Z. Lin, F. Lin and C. R. C. Wang, J. Chinese Chem. Soc., 2004, 51, 239-242.

71 S. Yu, W. Zhang, W. Liu, W. Zhu, R. Guo, Y. Wang, D. Zhang and J. Wang, Nanotechnology, 2015, 26, 145703.

72 T. Huang, J. A. Holden, D. E. Heath, N. M. O'BrienSimpson and A. J. O'Connor, Nanoscale, 2019, 11, 14937-14951.

73 X. D. Shi, Y. Q. Tian, J. L. Wu and S. Y. Wang, Crit. Rev. Food Sci. Nutr., 2020, 1-12.

74 B. Fardsadegh, H. Vaghari, R. Mohammad-Jafari, Y. Najian and H. Jafarizadeh-Malmiri, Green Process. Synth., 2019, 8, 191-198.

75 C. Mellinas, A. Jiménez and M. C. Garrigós, Molecules, 2019, 24, 4048.

76 Y. Shin, J. M. Blackwood, I.-T. Bae, B. W. Arey and G. J. Exarhos, Mater. Lett., 2007, 61, 4297-4300.

77 R. Abbasian and H. Jafarizadeh-Malmiri, Open Agric., 2020, 5, 761-767.

78 M. Iranifam, M. Fathinia, T. S. Rad, Y. Hanifehpour, A. R. Khataee and S. W. Joo, Talanta, 2013, 107, 263-269.

79 H. Chen, J. B. Yoo, Y. Liu and G. Zhao, Electron. Mater. Lett., 2011, 7, 333-336.
80 C. Xu, L. Qiao, L. Ma, Y. Guo, X. Dou, S. Yan, B. Zhang and A. Roman, Int. J. Nanomed., 2019, 14, 4491-4502.

81 X. Wang, X. Pan and G. M. Gadd, Sci. Total Environ., 2019, 668, 303-309.

82 T. Wang, L. Yang, B. Zhang and J. Liu, Colloids Surf., B, 2010, 80, 94-102.

83 A. V. Tugarova and A. A. Kamnev, Talanta, 2017, 174, 539-547.

84 A. V. Tugarova, P. V. Mamchenkova, Y. A. Dyatlova and A. A. Kamnev, Spectrochim. Acta, Part A, 2018, 192, 458-463.

85 A. V. Tugarova, P. V. Mamchenkova, V. A. Khanadeev and A. A. Kamnev, New Biotechnol., 2020, 58, 17-24.

86 S. K. Torres, V. L. Campos, C. G. León, S. M. RodríguezLlamazares, S. M. Rojas, M. González, C. Smith and M. A. Mondaca, J. Nanopart. Res., 2012, 14, 1-9.

87 S. Shoeibi and M. Mashreghi, J. Trace Elem. Med. Biol., 2017, 39, 135-139.

88 C. H. Ramamurthy, K. S. Sampath, P. Arunkumar, M. S. Kumar, V. Sujatha, K. Premkumar and C. Thirunavukkarasu, Bioprocess Biosyst. Eng., 2013, 36, 1131-1139.

89 K. Anu, S. Devanesan, R. Prasanth, M. S. AlSalhi, S. Ajithkumar and G. Singaravelu, J. King Saud Univ. Sci., 2020, 32, 2520-2526.

90 L. Gunti, R. S. Dass and N. K. Kalagatur, Front. Microbiol., 2019, 10, 931.

91 M. Abinaya, B. Vaseeharan, R. Rekha, S. Shanthini, M. Govindarajan, N. S. Alharbi, S. Kadaikunnan, J. M. Khaled and M. N. Al-Anbr, J. Photochem. Photobiol. B Biol., 2019, 192, 55-67.

92 S. Bharathi, S. Kumaran, G. Suresh, M. Ramesh, V. Thangamani, S. R. Pugazhvendan and K. Sathiyamurthy, Biocatal. Agric. Biotechnol., 2020, 27, 101655.

93 M. Borowska, E. Pawlik and K. Jankowski, Mon. Chem. Chem. Mon., 2020, 151, 1283-1290.

94 G. S. El-Sayyad, H. S. El-Bastawisy, M. Gobara and A. I. ElBatal, Biol. Trace Elem. Res., 2020, 195, 323-342.

95 A. H. Hashem, A. M. A. Khalil, A. M. Reyad and S. S. Salem, Biol. Trace Elem. Res., 2021, 199, 3998-4008.

96 M. Kapur, K. Soni and K. Kohli, Adv. Tech. Biol. Med., 2017, $5,1-7$.

97 V. Alagesan and S. Venugopal, Bionanoscience, 2019, 9, 105-116.

98 N. A. Mulla, S. V. Otari, R. A. Bohara, H. M. Yadav and S. H. Pawar, Mater. Lett., 2020, 264, 127353.

99 B. Fardsadegh and H. Jafarizadeh-Malmiri, Green Process. Synth., 2019, 8, 399-407.

100 N. S. Khoei, S. Lampis, E. Zonaro, K. Yrjälä, P. Bernardi and G. Vallini, New Biotechnol., 2017, 34, 1-11.

101 K. Kokila, N. Elavarasan and V. Sujatha, New J. Chem., 2017, 41, 7481-7490.

102 K. S. Prasad, H. Patel, T. Patel, K. Patel and K. Selvaraj, Colloids Surf., B, 2013, 103, 261-266.

103 G. M. Khiralla and B. A. El-Deeb, LWT - Food Sci. Technol., 2015, 63, 1001-1007. 
104 P. Korde, S. Ghotekar, T. Pagar, S. Pansambal, R. Oza and D. Mane, J. Chem. Rev., 2020, 2, 157-168.

105 R. Hassanien, A. A. I. Abed-Elmageed and D. Z. Husein, ChemistrySelect, 2019, 4, 9018-9026.

106 M. Karami, S. Asri-Rezaei, B. Dormanesh and A. Nazarizadeh, Int. J. Radiat. Biol., 2018, 94, 17-27.

107 E. Piacenza, A. Presentato, B. Heyne and R. J. Turner, Nanophotonics, 2020, 9, 3615-3628.

108 B. Afzal, D. Yasin, S. Husain, A. Zaki, P. Srivastava, R. Kumar and T. Fatma, Biocatal. Agric. Biotechnol., 2019, 21, 101307.

109 S. Prasanth and C. Sudarsanakumar, New J. Chem., 2017, 41, 9521-9530.

110 H. Kumar, K. Bhardwaj, E. Nepovimova, K. Kuča, D. S. Dhanjal, S. Bhardwaj, S. K. Bhatia, R. Verma and D. Kumar, Nanomaterials, 2020, 10, 1-31.

111 X. Ma and H. Yu, Yale J. Biol. Med., 2006, 79, 85-94.

112 M. J. Thun, J. O. DeLancey, M. M. Center, A. Jemal and E. M. Ward, Carcinogenesis, 2010, 31, 100-110.

113 E. J. Devlin, L. A. Denson and H. S. Whitford, J. Pain Symptom Manage, 2017, 54, 245-258.

114 Q. Tan, J. Li, H. Yin, L. Wang, W. Tang, F. Zhao, X. Liu and H. Zeng, Invest. New Drugs, 2010, 28, 205-215.

115 I. M. Puspitasari, R. Abdulah, C. Yamazaki, S. Kameo, T. Nakano and H. Koyama, Radiat. Oncol., 2014, 9, 125.

116 E. Yakubov, M. Buchfelder, I. Y. Eyüpoglu and N. E. Savaskan, Biol. Trace Elem. Res., 2014, 161, 246-254.

117 S. O. Evans, P. F. Khairuddin and M. B. Jameson, Anticancer Res., 2017, 37, 6497 LP-6509 LP.

118 H. Song, I. Hur, H. Park, J. Nam, G. Bin Park, K. H. Kong, Y. M. Hwang, Y. S. Kim, D. H. Cho, W. J. Lee and D. Y. Hur, Immune Netw., 2009, 9, 236.

119 Y.-C. Chen, K. S. Prabhu, A. Das and A. M. Mastro, Int. J. Cancer, 2013, 133, 2054-2064.

120 C. D. Davis, P. A. Tsuji and J. A. Milner, Annu. Rev. Nutr., 2012, 32, 73-95.

121 R. V. S. Lavu, T. Van De Wiele, V. L. Pratti, F. Tack and G. Du Laing, Food Chem., 2016, 197, 382-387.

122 S. J. Fairweather-Tait, R. Collings and R. Hurst, Am. J. Clin. Nutr., 2010, 91, 1484S-1491S.

123 D. N. Ekoue, S. Zaichick, K. Valyi-Nagy, M. Picklo, C. Lacher, K. Hoskins, M. A. Warso, M. G. Bonini and A. M. Diamond, J. Trace Elem. Med. Biol., 2017, 39, 227-233.

124 E. N. Ali, S. M. El-Sonbaty and F. M. Salem, Int. J. Pharmacol. Biol. Sci., 2013, 2, 38-46.

125 A. V. Pansare, D. K. Kulal, A. A. Shedge and V. R. Patil, Dalt. Trans., 2016, 45, 12144-12155.

126 K. S. Prasad and K. Selvaraj, Biol. Trace Elem. Res., 2014, 157, 275-283.

127 J. F. Ramos, P. A. Tran and T. J. Webster, in 2012 38th Annual Northeast Bioengineering Conference (NEBEC), IEEE, 2012, pp. 185-186.

128 T. H. D. Nguyen, B. Vardhanabhuti, M. Lin and A. Mustapha, Food Control, 2017, 77, 17-24.

129 W. Zhang, Z. Chen, H. Liu, L. Zhang, P. Gao and D. Li, Colloids Surf., B, 2011, 88, 196-201.
130 G. Sharma, A. Sharma, R. Bhavesh, J. Park, B. Ganbold, J.S. Nam and S.-S. Lee, Molecules, 2014, 19, 2761-2770.

131 R. Shubharani, M. Mahesh and V. N. Yogananda Murthy, J. Nanomed. Nanotechnol., 2019, 10, 1-7.

132 J. Vyas and S. Rana, Int. J. Phytomed., 2017, 9, 634.

133 M. H. Yazdi, M. Mahdavi, E. Faghfuri, M. A. Faramarzi, Z. Sepehrizadeh, Z. M. Hassan, M. Gholami and A. R. Shahverdi, Iran J. Biotechnol., 2015, 13, 1-9.

134 M. H. Yazdi, M. Mahdavi, N. Setayesh, M. Esfandyar and A. R. Shahverdi, DARU J. Pharm. Sci., 2013, 21, 33.

135 L. Fritea, V. Laslo, S. Cavalu, T. Costea and S. I. Vicas, Stud. Univ. Vasile Goldis Arad. Ser. Stiint. Vietii (Life Sci. Ser.), 2017, 27, 203-208.

136 A. A. Kamnev, P. V. Mamchenkova, Y. A. Dyatlova and A. V. Tugarova, J. Mol. Struct., 2017, 1140, 106-112.

137 H. Wu, X. Li, W. Liu, T. Chen, Y. Li, W. Zheng, C. W.-Y. Man, M.-K. Wong and K.-H. Wong, J. Mater. Chem., 2012, 22, 9602.

138 V. C. Tan, A. Hinchman, R. Williams, P. A. Tran and K. Fox, Biointerphases, 2018, 13, 06D301.

139 C. Ferro, H. F. Florindo and H. A. Santos, Adv. Healthcare Mater., 2021, 10, 2100598.

140 H. El-Ramady, N. Abdalla, H. S. Taha, T. Alshaal, A. El-Henawy, S. E.-D. A. Faizy, M. S. Shams, S. M. Youssef, T. Shalaby, Y. Bayoumi, N. Elhawat, S. Shehata, A. Sztrik, J. Prokisch, M. Fári, É. DomokosSzabolcsy, E. A. Pilon-Smits, D. Selmar, S. Haneklaus and E. Schnug, Environ. Chem. Lett., 2016, 14, 123-147.

141 G. N. Schrauzer, J. Nutr., 2000, 130, 1653-1656.

142 M. Shakibaie, M. R. Khorramizadeh, M. A. Faramarzi, O. Sabzevari and A. R. Shahverdi, Biotechnol. Appl. Biochem., 2010, 56, 7-15.

143 F. Yang, Q. Tang, X. Zhong, Y. Bai, T. Chen, Y. Zhang, Y. Li and W. Zheng, Int. J. Nanomed., 2012, 7, 835.

144 C. Ip, J. Nutr., 1998, 128, 1845-1854.

145 X. D. Shi, Y. Q. Tian, J. L. Wu and S. Y. Wang, Crit. Rev. Food Sci. Nutr., 2020, 0, 1-12.

146 A. Khurana, S. Tekula, M. A. Saifi, P. Venkatesh and C. Godugu, Biomed. Pharmacother., 2019, 111, 802-812.

147 M. P. Rayman, Proc. Nutr. Soc., 2005, 64, 527-542.

148 M. Wallenberg, S. Misra and M. Björnstedt, Basic Clin. Pharmacol. Toxicol., 2014, 114, 377-386.

149 L. V. Papp, J. Lu, A. Holmgren and K. K. Khanna, Antioxid. Redox Signal., 2007, 9, 775-806.

150 J. F. Combs Gerald, Nutrients, 2015, 7, 2209-2236.

151 K. S. Prasad and K. Selvaraj, Biol. Trace Elem. Res., 2014, 157, 275-283.

152 M. S. Ahmad, M. M. Yasser, E. N. Sholkamy, A. M. Ali and M. M. Mehanni, Int. J. Nanomed., 2015, 10, 3389.

153 Y. Li, X. Li, Y.-S. Wong, T. Chen, H. Zhang, C. Liu and W. Zheng, Biomaterials, 2011, 32, 9068-9076.

154 M. A. Rezvanfar, M. A. Rezvanfar, A. R. Shahverdi, A. Ahmadi, M. Baeeri, A. Mohammadirad and M. Abdollahi, Toxicol. Appl. Pharmacol., 2013, 266, 356-365.

155 K. K. Vekariya, J. Kaur and K. Tikoo, Toxicol. Appl. Pharmacol., 2013, 268, 212-220. 
156 S. A. Wadhwani, U. U. Shedbalkar, R. Singh and B. A. Chopade, Appl. Microbiol. Biotechnol., 2016, 100, 2555-2566.

157 Z. Ping, T. Liu, H. Xu, Y. Meng, W. Li, X. Xu and L. Zhang, Nano Res., 2017, 10, 3775-3789.

158 D. Zeng, J. Zhao, K.-H. Luk, S.-T. Cheung, K.-H. Wong and T. Chen, J. Agric. Food Chem., 2019, 67, 2865-2876.

159 A. Thubagere and B. M. Reinhard, ACS Nano, 2010, 4, 3611-3622.

160 S. Tang, T. Wang, M. Jiang, C. Huang, C. Lai, Y. Fan and Q. Yong, Int. J. Biol. Macromol., 2019, 128, 444-451.

161 X. Gao, X. Li, J. Mu, C.-T. Ho, J. Su, Y. Zhang, X. Lin, Z. Chen, B. Li and Y. Xie, Int. J. Biol. Macromol., 2020, 152, 605-615.

162 T. P. A. Devasagayam, J. C. Tilak, K. K. Boloor, K. S. Sane, S. S. Ghaskadbi and R. D. Lele, J. Assoc. Phys., 2004, 52, 794-804.

163 J. M. C. Gutteridge, Chem. - Biol. Interact., 1994, 91, 133-140.

164 S. Menon and V. K. Shanmugam, J. Trace Elem. Med. Biol., 2020, 62, 126549.

165 E. E. Battin, M. T. Zimmerman, R. R. Ramoutar, C. E. Quarles and J. L. Brumaghim, Metallomics, 2011, 3, 503-512.

166 J. T. Rotruck, A. L. Pope, H. E. Ganther, A. B. Swanson, D. G. Hafeman and W. G. Hoekstra, Science, 1973, 179, 588-590.

167 G. Zhang, X. Yao, C. Wang, D. Wang and G. Wei, J. Biotechnol., 2019, 304, 89-96.

168 X. Zhai, C. Zhang, G. Zhao, S. Stoll, F. Ren and X. Leng, J. Nanobiotechnology, 2017, 15, 1-12.

169 L. Gunti, R. S. Dass and N. K. Kalagatur, Front. Microbiol., 2019, 10, 1-17.

170 H. Kong, J. Yang, Y. Zhang, Y. Fang, K. Nishinari and G. O. Phillips, Int. J. Biol. Macromol., 2014, 65, 155-162.

171 A. Kumar and K. S. Prasad, J. Biotechnol., 2021, 325, 152-163.

172 W. Deng, Q. Xie, H. Wang, Z. Ma, B. Wu and X. Zhang, Nanomedicine, 2017, 13, 1965-1974.

173 Y. Liu, S. Zeng, Y. Liu, W. Wu, Y. Shen, L. Zhang, C. Li, H. Chen, A. Liu, L. Shen, B. Hu and C. Wang, Int. J. Biol. Macromol., 2018, 114, 632-639.

174 S. Al-Quraishy, M. Adkhil and A. E. A. Moneim, Int. J. Nanomed., 2015, 10, 6741-6756.

175 S. Zeng, Y. Ke, Y. Liu, Y. Shen, L. Zhang, C. Li, A. Liu, L. Shen, X. Hu, H. Wu, W. Wu and Y. Liu, Colloids Surf., B, 2018, 170, 115-121.

176 Q. Ge, L. Chen, M. Tang, S. Zhang, L. Liu, L. Gao, S. Ma, M. Kong, Q. Yao, F. Feng and K. Chen, Eur. J. Pharmacol., 2018, 833, 50-62.

177 W. Deng, H. Wang, B. Wu and X. Zhang, Acta Pharm. Sin. B, 2019, 9, 74-86.

178 I. Galan-Chilet, M. Grau-Perez, G. De Marco, E. Guallar, J. C. Martin-Escudero, A. Dominguez-Lucas, I. GonzalezManzano, R. Lopez-Izquierdo, L. S. Briongos-Figuero, J. Redon, F. J. Chaves and M. Tellez-Plaza, Redox Biol., 2017, 12, 798-805.
179 H. Grundmann, M. Aires-de-Sousa, J. Boyce and E. Tiemersma, Lancet, 2006, 368, 874-885.

180 G. A. Pankey, J. Antimicrob. Chemother., 2005, 56, 470-480. 181 J. N. Steenbergen, J. Alder, G. M. Thorne and F. P. Tally, J. Antimicrob. Chemother., 2005, 55, 283-288.

182 A. A. Ionin, A. K. Ivanova, R. A. Khmel'nitskii, Y. V. Klevkov, S. I. Kudryashov, A. O. Levchenko, A. A. Nastulyavichus, A. A. Rudenko, I. N. Saraeva, N. A. Smirnov, D. A. Zayarny, S. A. Gonchukov and E. R. Tolordava, Laser Phys. Lett., 2018, 15, 15604.

183 P. Sonkusre and S. Singh Cameotra, Colloids Surf., B, 2015, 136, 1051-1057.

184 S. Qayyum and A. U. Khan, MedChemComm, 2016, 7, 1479-1498. 185 L. Yan, Z. Gu and Y. Zhao, Chem. - Asian J., 2013, 8, 2342-2353.

186 X. Huang, X. Chen, Q. Chen, Q. Yu, D. Sun and J. Liu, Acta Biomater., 2016, 30, 397-407.

187 A. K. Mittal, S. Kumar and U. C. Banerjee, J. Colloid Interface Sci., 2014, 431, 194-199.

188 S. Menon, K. S. S. Devi, H. Agarwal and V. K. Shanmugam, Colloid Interface Sci. Commun., 2019, 29, 1-8.

189 H. Hariharan, N. A. Al-Harbi, P. Karuppiah and S. K. Rajaram, Chalcogenide Lett, 2012, 9, 509-515.

190 E. Zonaro, S. Lampis, R. J. Turner, S. Junaid and G. Vallini, Front. Microbiol., 2015, 6, 1-11.

191 E. Kheradmand, F. Rafii, M. H. Yazdi, A. A. Sepahi, A. R. Shahverdi and M. R. Oveisi, DARU, J. Pharm. Sci., 2014, 22, 1-6.

192 J. Yip, L. Liu, K. H. Wong, P. H. M. Leung, C. W. M. Yuen and M. C. Cheung, J. Appl. Polym. Sci., 2014, 131, 8886-8893.

193 M. Shakibaie, N. S. Mohazab and S. A. Ayatollahi Mousavi, Jundishapur J. Microbiol., 2015, 8, 1-4.

194 J. W. Baddley, T. P. Stroud, D. Salzman and P. G. Pappas, Clin. Infect. Dis., 2001, 32, 1319-1324.

195 B. Vogelman, S. Gudmundsson, J. Leggett, J. Turnidge, S. Ebert and W. A. Craig, J. Infect. Dis., 1988, 158, 831-847.

196 W. Craig, Eur. J. Clin. Microbiol. Infect. Dis., 1993, 12, S6-S8.

197 W. A. Craig, Ann. Intern. Med., 1987, 106, 900.

198 P. Jamshidi, S. Soflaei and H. Kooshki, Adv. Environ. Biol., 2014, 1228-1239.

199 S. Soflaei, A. Dalimi, A. Abdoli, M. Kamali, V. Nasiri, M. Shakibaie and M. Tat, Comp. Clin. Path., 2014, 23, 15-20.

200 H. Mahmoudvand, M. Shakibaie, R. Tavakoli, S. Jahanbakhsh and I. Sharifi, Iran. J. Parasitol., 2014, 9, 452-460.

201 D. Wlodkowic, W. Telford, J. Skommer and Z. Darzynkiewicz, Methods Cell Biol., 2011, 103, 55-98.

202 H. Mahmoudvand, M. Fasihi Harandi, M. Shakibaie, M. R. Aflatoonian, N. ZiaAli, M. S. Makki and S. Jahanbakhsh, Int. J. Surg., 2014, 12, 399-403.

203 D. P. Biswas, N. M. O’Brien-Simpson, E. C. Reynolds, A. J. O'Connor and P. A. Tran, J. Colloid Interface Sci., 2018, 515, 78-91.

204 S. Ramya, T. Shanmugasundaram and R. Balagurunathan, J. Trace Elem. Med. Biol., 2015, 32, 30-39.

205 A. Bhattacharjee, A. Basu, P. Ghosh, J. Biswas and S. Bhattacharya, J. Biomater. Appl., 2014, 29, 303-317. 
206 A. Bhattacharjee, A. Basu, J. Biswas, T. Sen and S. Bhattacharya, Mol. Cell. Biochem., 2017, 424, 13-33.

207 F. Gao, Q. Yuan, L. Gao, P. Cai, H. Zhu, R. Liu, Y. Wang, Y. Wei, G. Huang, J. Liang and X. Gao, Biomaterials, 2014, 35, 8854-8866.
208 C. E. Hassan and T. J. Webster, Int. J. Nanomed., 2016, 11, 3641-3654.

209 B. Yu, T. Liu, Y. Du, Z. Luo, W. Zheng and T. Chen, Colloids Surf., B, 2016, 139, 180-189. 